San Jose State University

SJSU ScholarWorks

Master's Theses

Master's Theses and Graduate Research

Summer 2011

\title{
WRF-Model Performance for Wind Power Forecasting in the Coast Ranges of Central California
}

\author{
Kevin Thomas Clifford \\ San Jose State University
}

Follow this and additional works at: https://scholarworks.sjsu.edu/etd_theses

\section{Recommended Citation}

Clifford, Kevin Thomas, "WRF-Model Performance for Wind Power Forecasting in the Coast Ranges of Central California" (2011). Master's Theses. 4043.

DOI: https://doi.org/10.31979/etd.4aqf-egnn

https://scholarworks.sjsu.edu/etd_theses/4043

This Thesis is brought to you for free and open access by the Master's Theses and Graduate Research at SJSU ScholarWorks. It has been accepted for inclusion in Master's Theses by an authorized administrator of SJSU ScholarWorks. For more information, please contact scholarworks@sjsu.edu. 


\title{
WRF-MODEL PERFORMANCE FOR WIND POWER FORECASTING IN THE COAST RANGES OF CENTRAL CALIFORNIA
}

\author{
A Thesis \\ Presented to \\ The Faculty of the Department of Meteorology and Climate Science \\ San José State University
}

\author{
In Partial Fulfillment \\ of the Requirements for the Degree \\ Masters of Science
}

by

Kevin T. Clifford

August 2011 
(C) 2011

Kevin T. Clifford

ALL RIGHTS RESERVED 
The Designated Thesis Committee Approves the Thesis Titled

WRF-MODEL PERFORMANCE FOR WIND POWER FORECASTING IN THE COAST RANGES OF CENTRAL CALIFORNIA

\author{
by \\ Kevin T. Clifford \\ APPROVED FOR THE DEPARTMENT OF METEOROLOGY AND CLIMATE SCIENCE \\ SAN JOSÉ STATE UNIVERSITY \\ August 2011 \\ Dr. Craig Clements \\ Department of Meteorology and Climate Science \\ Dr. Alison F.C. Bridger \\ Department of Meteorology and Climate Science \\ Dr. Martin Leach \\ Department of Meteorology and Climate Science \\ Dr. Sharon Zhong \\ Michigan State University, Department of Geography
}




\title{
ABSTRACT \\ WRF-MODEL PERFORMANCE FOR WIND POWER FORECASTING IN THE COAST RANGES OF CENTRAL CALIFORNIA
}

\author{
by Kevin T. Clifford
}

This study describes the verification of modeled low-level atmospheric conditions in the complex terrain surrounding the Altamont Pass wind farm near Livermore, California, USA. The Weather Research and Forecasting model (WRF) was used to (1) simulate the Coast Range near-surface winds, and (2) simulate low-level flow and available wind power in the Altamont Pass. Standard statistical verifications were performed against low-level wind speed observations at seventeen sites. Available wind power was calculated using equivalent wind speed and was evaluated for six areas within Altamont Pass. The overall results include good model performance for the regional near-surface winds, acceptable to good model performance for the Altamont Pass lowlevel winds, and good model performance for Altamont Pass capacity factor simulations. More specifically, while modeled hour-to-hour variance was not exact, WRF-modeled wind speeds were close to those observed. Combined with agreement between both modeled and observed wind direction and atmospheric stability, WRF modeled capacity factors were within the range of observed capacity factors in $93 \%$ of the instances. Therefore, WRF modeled winds and derived wind power can be used as a wind power forecasting tool for Altamont Pass and possibly other coastal complex terrain regions. 


\section{ACKNOWLEDGEMENTS}

I would like to acknowledge the members of my thesis committee: Drs. Craig Clements, Alison Bridger, Martin Leach, and Sharon Zhong. As my advisor, Dr.

Clements deserves special acknowledgement for all of his assistance and support over the past two years. His help with the experimental design and writing process is immeasurable. Drs. Bridger, Leach, and Zhong, all have expertise in modeling studies and I am grateful for their assistance in the writing process.

I would also like to thank Michael Voss for helping me set-up and develop WRF. His expertise in weather forecasting, computer programming, and synoptic weather was invaluable, and I greatly appreciate all of his assistance and patience.

I would like to thank my fellow graduate students at San Jose State University for their support and knowledge. In particular, I would like to thank Estatio Gutierrez for his assistance in WRF development, and Allison Charland and Daisuke Seto for their insights.

Additionally, I would like to thank an undisclosed wind power company for providing essential data. 


\section{TABLE OF CONTENTS}

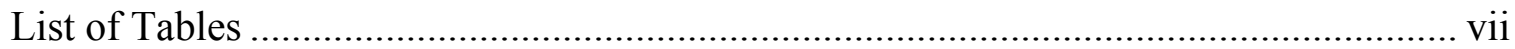

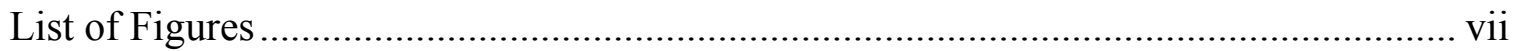

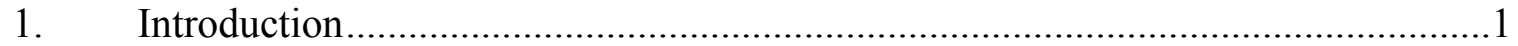

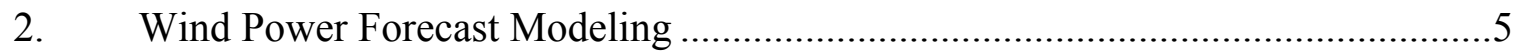

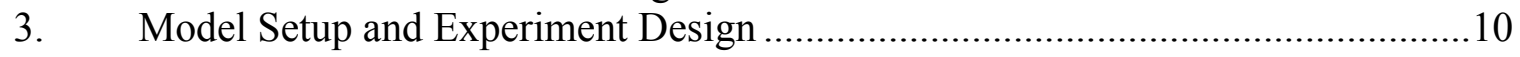

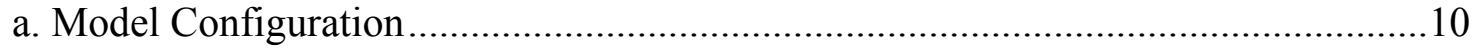

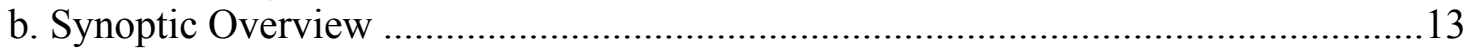

c. Observational Data and Statistical Comparisons ................................................... 14

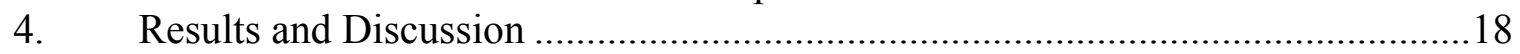

a. Near-Surface Wind Field .............................................................................. 18

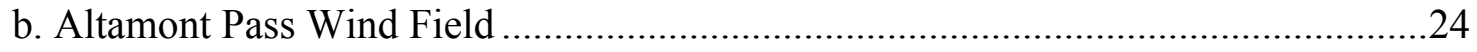

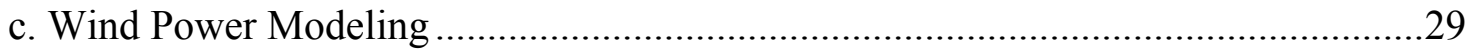

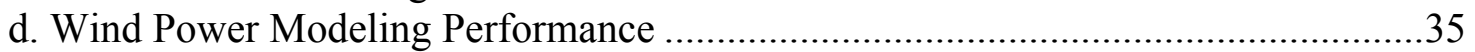

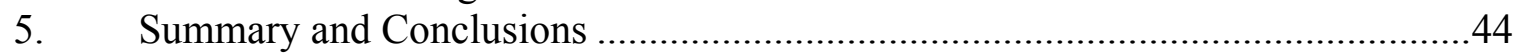

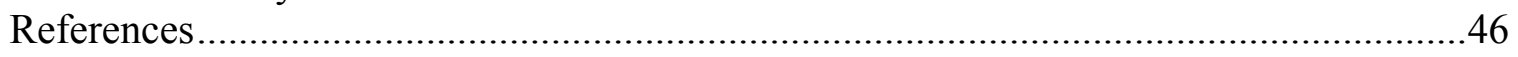

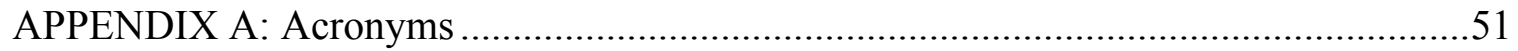




\section{LIST OF TABLES}

TABLE 1. Atmospheric Stability Classes....................................... 6

TABLE 2. WRF Forecast Case Study Dates......................................... 13

TABLE 3. RAWS, METAR, CWOP, and CARB Observation Sites.................... 15

TABLE 4. LLNL Observation Sites.......................................... 16

TABLE 5. Modeled Wind Speed Statistical Performance Grades........................17

TABLE 6. Modeled CF Performance..............................................41 


\section{LIST OF FIGURES}

FIG. 1. Spatial Configuration of WRF Domains............................... 11

FIG. 2. Areas 1 - 6 of the Altamont Pass Wind Farm............................... 12

FIG. 3. Near-Surface Wind Speed MAE Statistic Plots............................ 19

FIG. 4. Near-Surface Wind Speed RMSE Statistic Plots........................... 20

FIG. 5. Near-Surface Wind speed ACC Statistic Plots............................. 21

FIG. 6. Modeled versus Observed Near-Surface Wind Direction..................... 22

FIG. 7. Hub-Height Wind Speed MAE, RMSE, and ACC Statistic Plots............... 25

FIG. 8. Modeled versus Observed Hub-Height Wind Direction....................... 26

FIG. 9. Modeled versus Observed Turbulence Intensity............................27

FIG. 10. WRF-Modeled Hub-Height Flow in Altamont Pass, 1100 LT 24 July 2010.....30

FIG. 11. WRF-Modeled Hub-Height Flow in Altamont Pass, 1400 LT 24 July 2010.....30

FIG. 12. WRF-Modeled Hub-Height Flow in Altamont Pass, 1700 LT 24 July 2010.....31

FIG. 13. WRF-Modeled Hub-Height Flow in Altamont Pass, 2000 LT 24 July 2010.....31

FIG. 14. WRF-Modeled Hub-Height Flow in Altamont Pass, 2300 LT 24 July 2010.....32

FIG. 15. WRF-Modeled Hub-Height Flow in Altamont Pass, 0200 LT 25 July 2010.....32

FIG. 16. WRF-Modeled Hub-Height Flow in Altamont Pass, 0500 LT 25 July 2010.....33

FIG. 17. WRF-Modeled Hub-Height Flow in Altamont Pass, 1100 LT 25 July 2010.......33

FIG. 18. Case 1 WRF Modeled versus Observed Daily CF............................ 36

FIG. 19. Case 2 WRF Modeled versus Observed Daily CF......................... 37

FIG. 20. Case 3 WRF Modeled versus Observed Daily CF........................... 38 
FIG. 21. Case 4 WRF Modeled versus Observed Daily CF............................. 39

FIG. 22. Case 5 WRF Modeled versus Observed Daily CF............................. 40 


\section{Introduction}

With ever increasing energy needs, US grid-connected wind power capacity has increased tenfold since the 1980s (Wiser and Bolinger 2008). This fast growing power source across the world and the United States has become available in part from wind power production in complex terrain due to flow enhancement and channeling by the topographic features (Gazzilli et al. 2001). California is one of the leading regions of the world for wind power production, with several large wind farms located in the California Coast Ranges, including Altamont Pass (Sezgen et al. 1998). However, before wind power generated at these locations can be integrated into the power network, accurate estimates of its potential contribution are necessary to ensure efficient utilization (Brown et al. 1984). Therefore, accurate atmospheric modeling within complex terrain is essential for forecasting wind power production.

The California Coast Ranges, with elevations extending to $1300 \mathrm{~m}$ above mean sea level (MSL), create a topographic barrier separating the Pacific Ocean from California's low elevation Central Valley (Zaremba and Carroll 1999). From late-spring through mid-fall (LSMF), the eastern Pacific subtropical high-pressure region juxtaposes a thermal low pressure region over California's Central Valley, synoptically inducing onshore flow of stable marine air (Fosberg and Schroeder 1966; Burk and Thompson 1996). Daytime warming coupled with these synoptic conditions also creates a highly baroclinic marine inversion, leading to low-level jet formation near the coastal margin (Burk and Thompson 1996; Archer and Jacobson 2005). When the low-level flow is funneled into the San Francisco Bay and the marine air is forced over and through the 
rugged Coast Ranges, sea breeze and mountain circulations couple to enhance nearsurface wind speeds (Fosberg and Schroeder 1966; Burk and Thompson 1996; Zaremba and Carroll 1999), thus leading to increased available wind power in this region. There are three dynamically forced mountain circulations of stable air that can enhance wind speeds and available wind power in the Coast Ranges. They are flow acceleration due to the vertical compression of air, gap flow acceleration, and atmospheric wave formation.

The most consistent effect of mountainous terrain on atmospheric dynamics is the increased wind speed found at the mountain ridge crest. The vertical compression of air over a ridgeline causes acceleration of the airflow as it moves past the ridge crest, locally enhancing low-level wind speeds (Barry 1992). Increased frictional drag caused by mountain ruggedness slightly reduces wind speeds; however, crest wind speeds are still higher than the background flow even with the increased friction (Barry 1992).

Gap flow acceleration occurs through mountain passes that topographically channel flow in the gap-axis direction (Whiteman 2000). Synoptic scale pressure differences cause air to flow across the mountain barrier toward the lower pressure lee side. In the presence of mountain passes, air is funneled into and through the terrain gaps, removing it from geostrophic balance and causing wind speed acceleration along the pressure gradient (Doran and Zhong 2000). These low-level jets occur most frequently in LSMF afternoons and evenings and can result in wind speeds greater than $15 \mathrm{~m} \mathrm{~s}^{-1}$ (Doran and Zhong 2000; Jaramillo and Borja 2004; Sharp and Mass 2004). As stable air flows over a mountain range, energy is radiated away from the barrier by internal gravity waves (Doyle and Smith 2003). Whether this energy 
propagates vertically or horizontally depends on the mountain barrier, wind speed, and atmospheric stability (Doyle and Smith 2003; Zangl 2003). Generally, gravity waves cause energy radiation and wind speed maxima near the mountain ridge crest and lee side slope surfaces (Zangl 2003). Theoretically, for this to occur the Froude number $(F r=N a / U ; N$ is the Brunt Vaisala Frequency, $a$ is the mountain half-width, and $U$ is the horizontal wind speed) must approximately equal 1.0 (Zangl 2003). In the case of California's Coast Ranges, a Froude number of approximately 1.0 is possible during typical LSMF synoptic conditions. Given the range's narrow width and the onshore flow of stable marine air, for the correct background wind speed, gravity waves can further enhance wind speeds at the ridgeline crest and lee side slopes by 3 to $5 \mathrm{~m} \mathrm{~s}^{-1}$ (Zangl 2003).

Combining these three dynamically-forced circulations through a mountain pass results in the highest sustained wind speeds (Zangl 2003; Gaberšek and Durran 2004; Gaberšek and Durran 2006). Zangl (2003), and Gaberšek and Durran (2004) show that if the conditions for gravity wave formation are met, air descends through the gap, converting potential energy to kinetic energy and enhancing wind speeds by $7 \mathrm{~m} \mathrm{~s}^{-1}$ at the pass exit. Furthermore, because of surface frictional effects, a west to northwest synoptic wind direction relative to the gap axis results in the highest wind speed enhancement (Gaberšek and Durran 2006). These wind directions are commonly seen during typical LSMF synoptic conditions along the Coast Ranges (Burk and Thompson 1996). Combining these synoptic wind conditions with the high probability for gravity wave 
formation, the Coast Ranges are ideal for dynamically-enhanced winds and increased wind power production. 


\section{Wind Power Forecast Modeling}

Simulating wind power relies on several key diagnostic equations that combine several atmospheric parameters. The power (Watts) of wind flow at speed $U\left(\mathrm{~m} \mathrm{~s}^{-1}\right)$ through a wind turbine's rotor area $A\left(\mathrm{~m}^{2}\right)$ can be estimated by

$$
P=\frac{1}{2} \rho A U^{3}
$$

where $\rho\left(\mathrm{kg} \mathrm{m}^{-3}\right)$ is air density, which depends on atmospheric pressure and temperature (Jaramillo and Borja 2004). Wind power fluctuations are more dependent on the varying rotor area wind speed than atmospheric density, which varies little in time.

Previously it was believed that the wind speed at the center of the rotor area, i.e., hub-height wind speed, was sufficient for determining the rotor area average wind speed. However, Wharton and Lundquist (2010) showed that shear across the rotor caused by vertically varying atmospheric stability can have significant effects on wind power production. For example, hub-height wind speeds overestimate the rotor-averaged velocity by $1 \mathrm{~m} \mathrm{~s}^{-1}$ or more during stable conditions, while there is little to no overestimation in neutral or convective conditions. Using stability proxies such as horizontal turbulence intensity and turbulent kinetic energy, in combination with equivalent wind speed, reduces errors introduced by hub-height wind speed. Horizontal turbulence intensity,

$$
I_{U}=\frac{\sigma_{U}}{U(z)}
$$

is used to estimate boundary layer stability by dividing the wind speed standard deviation 
TABLE 1. Stability classes and wind shear for horizontal turbulence intensity $\left(I_{U}\right)$ and turbulent kinetic energy (TKE) (adapted from Wharton and Lundquist 2010).

\begin{tabular}{|c|c|c|c|}
\hline Stability Class & $I_{U}$ & $T K E$ & Shear in Rotor Area \\
\hline Strongly Stable & $I_{U}<0.08$ & $T K E<0.4$ & Highest \\
\hline Stable & $0.08<I_{U}<0.10$ & $0.4<T K E<0.6$ & High \\
\hline Neutral & $0.10<I_{U}<0.20$ & $0.6<T K E<1.0$ & Neutral \\
\hline Convective & $0.20<I_{U}<0.30$ & $1.0<T K E<1.4$ & Low \\
\hline Strongly Convective & $I_{U}>0.30$ & $T K E>1.4$ & Little to None \\
\hline
\end{tabular}

$\left(\sigma_{u} ; \mathrm{m} \mathrm{s}^{-1}\right)$ by the mean horizontal wind speed $(U)$ at height $z(\mathrm{~m})$ (Wharton and Lundquist 2010). High $I_{U}$ values indicate more convective conditions, while low $I_{U}$ values indicate more stable flow (Table 1). Turbulent Kinetic Energy (TKE) is another stability proxy and is defined by

$$
T K E=\frac{1}{2}\left(\overline{u^{\prime 2}}+\overline{v^{\prime 2}}+\overline{w^{\prime 2}}\right)
$$

where $\overline{u^{\prime 2}}, \overline{v^{\prime 2}}$, and $\overline{w^{\prime 2}}$ are the average of the square of the wind speed turbulence in the $u, v$, and $w$ directions (Wharton and Lundquist 2010). Assuming turbulence is isotropic in the $u, v$, and $w$ directions; $I_{U}$ and $T K E$ are related by

$$
I_{U}=\frac{\sqrt{\frac{2}{3} T K E}}{U(z)} .
$$

$I_{U}$ can then be used to infer a more accurate rotor average wind speed by calculating equivalent wind speed $\left(U_{\text {equiv }} ; \mathrm{m} \mathrm{s}^{-1}\right)$,

$$
U_{\text {equiv }}=\frac{2}{A} \int_{H-r}^{H+r} U_{I}(z)\left(r^{2}-H^{2}+2 H z-z^{2}\right)^{1 / 2} d z
$$

where $H$ is the turbine hub-height (m), $r$ is the rotor area radius (m), and $U_{I}(z)$ is the true 
flux wind speed at height $z(\mathrm{~m})$ (Wagner et al. 2009; Wharton and Lundquist 2010). $U_{I}(z)$ is calculated using the derivation of the average energy flux,

$$
U_{I}(z)=\sqrt[3]{U(z)^{3}\left(1+3 I_{U}{ }^{2}\right)},
$$

which includes turbulence and wind shear in the rotor area average wind speed (Wagner et al. 2009; Wharton and Lundquist 2010).

Wind turbines maximize their power production at their power output rating, $P_{R}$ (Watts) (Jaramillo and Borja 2004; Wharton and Lundquist 2010). However, this amount of power can only be delivered if the wind turbine is working at maximum capacity. The fraction of maximum power production at a given time is determined by the capacity factor,

$$
C F=\frac{P}{P_{R}},
$$

where $P$ (Watts) is the actual power output (Jaramillo and Borja 2004). $P$ is determined either by using equation (1) multiplied by several mechanical performance corrections, or by using a power curve supplied by the wind turbine manufacturer. Typically, modern wind turbines in the U.S. have an annual CF of 35 percent, with the most efficient turbines achieving an annual CF of 48 percent (Wiser and Bolinger 2009). From equations (1), (5), and (7), the variables that affect CF are wind speed and atmospheric stability. Therefore, any wind power forecasting approach for power network planning must be able to accurately simulate atmospheric stability and wind speed in the lower atmospheric boundary layer (Wharton and Lundquist 2010). 
Wind power forecasting relies on the predictability of atmospheric dynamics. Therefore, modeling systems that can accurately depict future atmospheric conditions are the most valuable resource for wind power forecasting. Evaluating model accuracy is accomplished by comparing simulated and observed atmospheric conditions at the same time. However, observations are point recordings, while model simulations represent spatial means determined by a model's horizontal and vertical grid spacing (Hanna and Yang 2001). Thus, differences are expected between observed and simulated conditions simply due to the differences of time and volume averages that each represents (Hanna and Yang 2001).

Many of the topographic features and atmospheric behaviors within complex terrain occur on a smaller spatial scale than the commonly used synoptic-scale forecasting models can simulate, resulting in limited near-surface model accuracy (Reid and Turner 2001). However, higher resolution mesoscale models, such as the Weather Research and Forecasting model (WRF, Skamarock et al. 2010), are better suited for resolving the near-surface atmospheric behavior in complex terrain (Rife et al. 2004; Žagar et al. 2006; Jimenez et al. 2010). It has previously been shown that WRF's crossmountain flow modeling with respect to blocking, channeling, orography, and thermal forcing all correlate to observations at an acceptable level of accuracy (Rife et al. 2004; Žagar et al. 2006; Jimenez et al. 2010). WRF best handles complex terrain dynamics for cross-mountain flow at well-exposed mountaintops, whereas inner-mountain valleys and basins prove to be the most difficult to accurately simulate (Žagar et al. 2006). 
Given these findings, this study was conducted to assess the accuracy and potential of WRF as a wind power forecasting tool by: (1) simulating the Coast Range near-surface winds; and (2) simulating low-level flow and available wind power within Altamont Pass. 


\section{Model Setup and Experiment Design}

Given WRF's ability to accurately model boundary layer dynamics in complex terrain (Rife et al. 2004; Žagar et al. 2006; Jimenez et al. 2010), a series of five case study forecasts were conducted during near ideal high wind power producing LSMF synoptic conditions to test WRF wind power modeling accuracy in Altamont Pass near Livermore, California, USA. The Altamont Pass wind farm is one of the world's largest and is nestled in the Diablo Range, a section of California's Coast Ranges $60 \mathrm{~km}$ east of San Francisco. The $300 \mathrm{~m}$ MSL Altamont Pass is in a highly complex area of topography, with the 600 to $1300 \mathrm{~m}$ MSL Diablo Range to the north and south, $500 \mathrm{~m}$ MSL Las Trampas hills and $180 \mathrm{~m}$ MSL Livermore Valley to the west, and the $0 \mathrm{~m}$ MSL northern San Joaquin Valley to the east (Figs. 1 and 2). Chaparral-type vegetation comprised of mostly open grassland with intermittent oak woodland covers the region. Combined with low intensity residential and agricultural land use, there are few substantial windbreaks upwind and within Altamont Pass.

\section{a. Model Configuration}

The mesoscale WRF modeling system (version 3.2; Skamarock et al. 2010) was configured with three domains using two-way nesting to attain a horizontal resolution of 


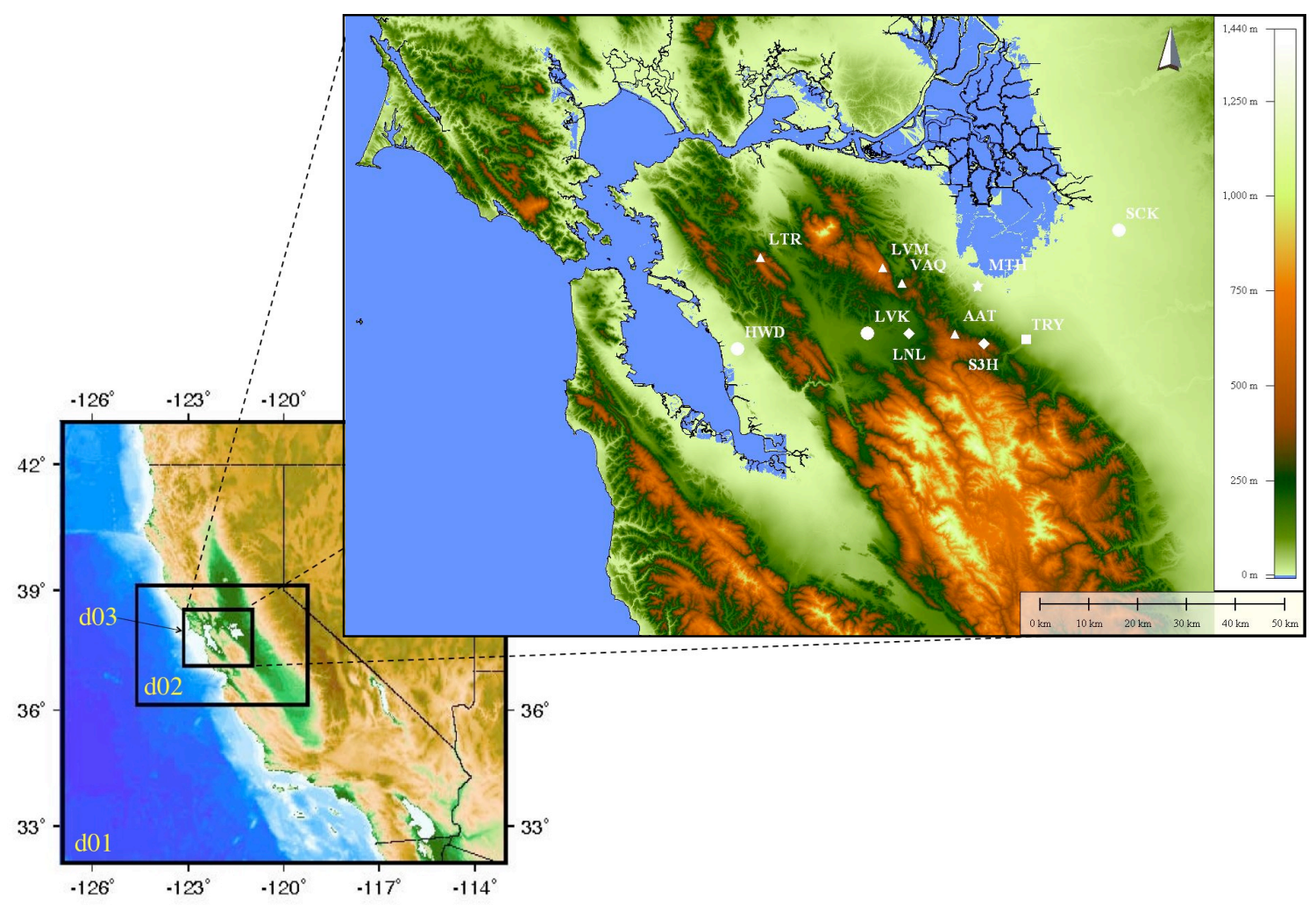

FIG. 1. Spatial configuration of domains, for the WRF simulation: three domains twoway nested with 9, 3, and $1 \mathrm{~km}$ horizontal resolution. Station locations are shown for the innermost domain. The comparison sites used for WRF evaluation are from the RAWS (triangles), METAR (circles), CARB (squares), CWOP (stars), and LLNL (diamonds) observation networks.

$1 \mathrm{~km}$ over the study area. The outermost domain centered over California is $1300 \mathrm{x} 1300$ $\mathrm{km}^{2}$ with a horizontal grid resolution of $9 \mathrm{~km}$ (Fig. 1). The intermediate domain centered over Central California has a horizontal grid resolution of $3 \mathrm{~km}$. Finally, the third domain with $1 \mathrm{~km}$ horizontal resolution was nested over the San Francisco Bay Area. The topographic data were obtained from the U.S. Geological Survey (USGS) global one-third arc-second dataset. A WRF configuration of 52 terrain-following hydrostatic pressure levels, with 18 levels below $300 \mathrm{~m}$ above ground level (AGL), and a top level of $50 \mathrm{hPa}$, was used in the vertical for all three domains. 


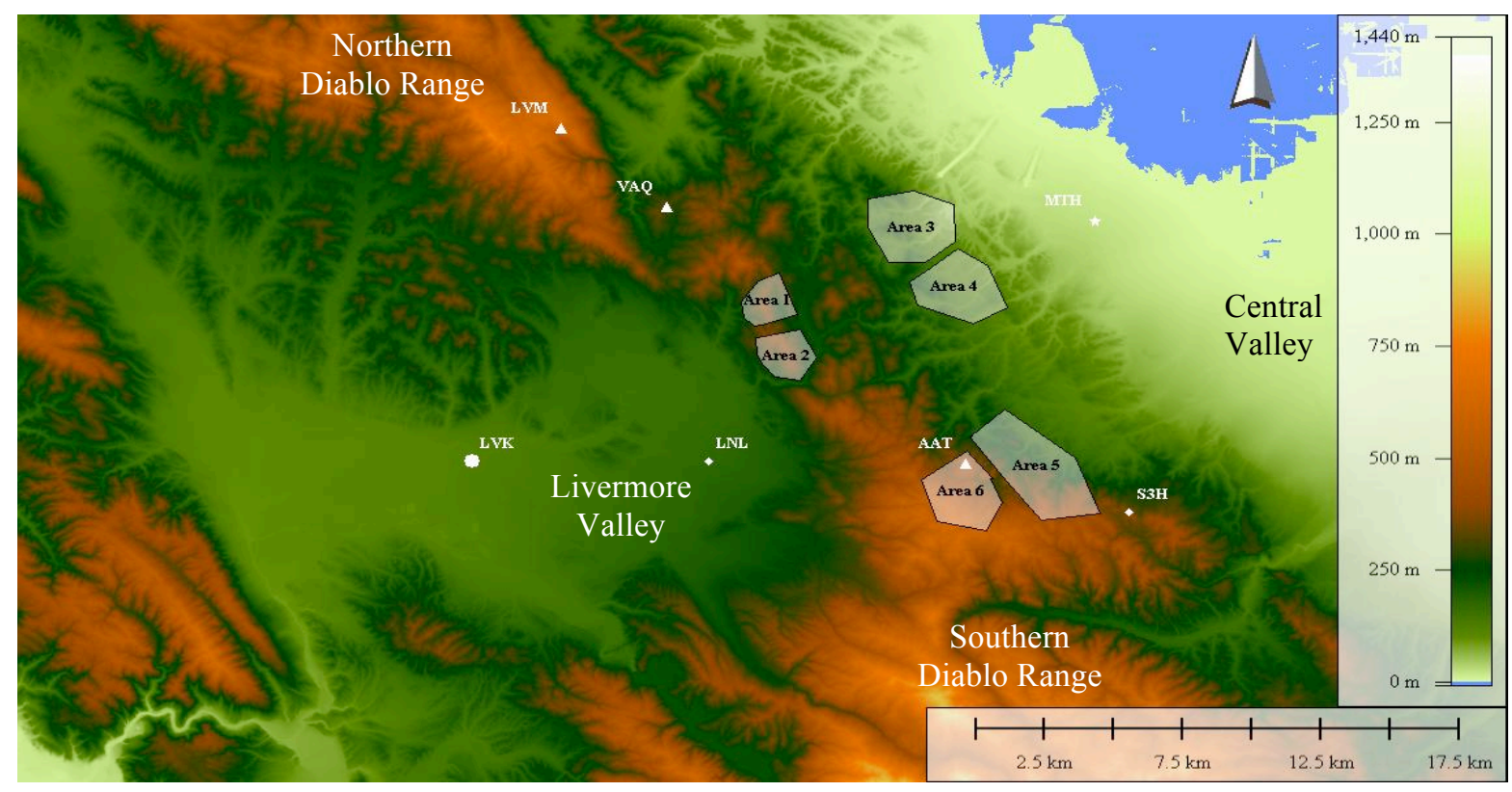

FIG. 2. Areas 1 - 6 of the Altamont Pass wind farm, near Livermore, California bordered by the Las Trampas Hills and Livermore Valley to the west, the Diablo Range to the north and south, and northern San Joaquin Valley to the east. Typical LSMF conditions promote westerly flow to funnel over and through the pass, resulting in wind speed enhancement from the pass crest extending to the lee side.

The physics parameterizations used within WRF were chosen from a host of available options. The longwave and shortwave radiation schemes are based on Mlawer et al. (1997) and Dudhia (1989), respectively. A version of the Kain and Fritsch (1990, 1993) scheme was used for the cumulus scheme parameterization. The Mellor-YamadaJanjic planetary boundary layer parameterization (Janjic 2003) was used for all three domains. The Ferrier microphysics scheme (Rogers et al. 2001) was used. Finally, a four-layer land surface model based on the Monin-Obukhov similarity theory (Janjic 1996) was used. The $1 \mathrm{~km}$ USGS land use/land cover system was used to determine the surface physical properties (Anderson et al. 1976). 
TABLE 2. Beginning and ending dates of WRF forecast case studies.

\begin{tabular}{|c|c|c|}
\hline Case & Beginning Date & Ending Date \\
\hline 1 & 0000 UTC 6 July 2010 & 1200 UTC 9 July 2010 \\
\hline 2 & 0000 UTC 18 July 2010 & 1200 UTC 21 July 2010 \\
\hline 3 & 0000 UTC 24 July 2010 & 1200 UTC 27 July 2010 \\
\hline 4 & 0000 UTC 29 July 2010 & 1200 UTC 1 August 2010 \\
\hline 5 & 0000 UTC 4 August 2010 & 1200 UTC 7 August 2010 \\
\hline
\end{tabular}

Initial and boundary conditions were obtained for each of the five case studies from the 0000 UTC $12 \mathrm{~km}$ horizontal-resolution North American Mesoscale model (NAM 218) forecasts, as would be done in an operational setting. The WRF model is initialized as a cold-start at 0000 UTC for each of the five cases and run for 84 hours, updating the boundary conditions every three hours and recording data every hour.

\section{b. Synoptic Overview}

Five 84-hour wind power forecasts using WRF were produced for the July 6 to August 82010 time period (Table 2). In all cases, the eastern Pacific subtropical surface high-pressure region was located several hundred kilometers off the North American west coast, with a thermal low-pressure region over the southwestern Great Basin. The exact location of the high- and low-pressure regions fluctuated throughout this time period, but the resulting surface pressure gradients were predominantly oriented east-west across Central California with NW to SW synoptic surface wind directions. Notable periods of a strong onshore pressure gradient were July 20, 26, 30, and August 4 and 5. A patchy to dense marine layer was usually found along the California coastline that typically intruded well inland during the night hours, and retreated back to the coast during the morning hours. There were little to no high- or mid-level clouds during all five cases. A $500 \mathrm{hPa}$ ridge with an axis aligned along the North American west coast 
also existed throughout this time period; however its exact strength and location fluctuated more so than the surface high pressure region. There were two instances of negatively tilted $500 \mathrm{hPa}$ troughs sweeping over the study area (July 20 and August 5 6), but did little to affect near-surface atmospheric behavior. More commonly $300 \mathrm{hPa}$ and $250 \mathrm{hPa}$ jets ahead of upper level troughs resulted in increased wind speeds throughout the atmospheric column (July 26 - 27 and July 29 - August 1).

\section{c. Observational Data and Statistical Comparisons}

The observational dataset used for model evaluation in the five case model runs was a combination of several quality-controlled sources, for a total of 17 comparison sites. Wind speed, wind direction, temperature, relative humidity, and sea-level pressure data were provided by nine Remote Automated Weather System (RAWS), Meteorological Aviation Report (METAR), California Air Resource Board (CARB), and Citizen Weather Observer Program (CWOP) meteorological towers (Fig. 1 and Table 3). Secondly, wind speed, wind direction, air temperature, air density, atmospheric pressure, and relative humidity data were provided by two of the Lawrence Livermore National Laboratories (LLNL) meteorological towers (Fig. 1 and Table 4). Lastly, an Altamont Pass wind power company provided hub-height wind speed, wind speed standard deviation, wind direction, and wind direction standard deviation data from six meteorological towers, as well as daily wind power production for each of their wind turbines (Fig. 2). WRF model values for all of the comparisons were extracted using a bilinear interpolation method. 
TABLE 3. Station information for RAWS, METAR, CWOP, and CARB observation sites.

\begin{tabular}{|c|c|c|c|c|}
\hline $\begin{array}{l}\text { Station } \\
\text { ID }\end{array}$ & Station Name & $\begin{array}{l}\text { Station } \\
\text { Elev. } \\
(\mathrm{m}) \\
\end{array}$ & $\begin{array}{c}\text { Data } \\
\text { Available }\end{array}$ & $\begin{array}{l}\text { AGL Elev. } \\
\text { of Variable } \\
(\mathrm{m})\end{array}$ \\
\hline AAT & $\begin{array}{c}\text { Altamont } \\
\text { Reservoir } \\
\text { RAWS }\end{array}$ & 437 & $\begin{array}{l}\text { Air Temperature } \\
\text { Relative Humidity } \\
\text { Wind Speed } \\
\text { Wind Direction }\end{array}$ & $\begin{array}{l}2 \\
2 \\
6 \\
6\end{array}$ \\
\hline HWD & $\begin{array}{c}\text { Hayward Air } \\
\text { Terminal }\end{array}$ & 14 & $\begin{array}{l}\text { Sea Level Pressure } \\
\text { Air Temperature } \\
\text { Relative Humidity } \\
\text { Wind Speed } \\
\text { Wind Direction }\end{array}$ & $\begin{array}{c}0 \\
2 \\
2 \\
10 \\
10\end{array}$ \\
\hline LTR & $\begin{array}{l}\text { Las Trampas } \\
\text { RAWS }\end{array}$ & 536 & $\begin{array}{c}\text { Air Temperature } \\
\text { Relative Humidity } \\
\text { Wind Speed } \\
\text { Wind Direction }\end{array}$ & $\begin{array}{c}2 \\
2 \\
10 \\
10\end{array}$ \\
\hline LVK & $\begin{array}{c}\text { Livermore } \\
\text { Municipal } \\
\text { Airport }\end{array}$ & 121 & $\begin{array}{c}\text { Sea Level Pressure } \\
\text { Air Temperature } \\
\text { Relative Humidity } \\
\text { Wind Speed } \\
\text { Wind Direction }\end{array}$ & $\begin{array}{c}0 \\
2 \\
2 \\
10 \\
10\end{array}$ \\
\hline LVM & $\begin{array}{l}\text { Mallory } \\
\text { Ridge } \\
\text { RAWS }\end{array}$ & 594 & $\begin{array}{c}\text { Air Temperature } \\
\text { Relative Humidity } \\
\text { Wind Speed } \\
\text { Wind Direction }\end{array}$ & $\begin{array}{l}2 \\
2 \\
6 \\
6\end{array}$ \\
\hline MTH & $\begin{array}{l}\text { Mountain } \\
\text { House } \\
\text { CWOP }\end{array}$ & 24 & $\begin{array}{l}\text { Sea Level Pressure } \\
\text { Air Temperature } \\
\text { Relative Humidity } \\
\text { Wind Speed } \\
\text { Wind Direction }\end{array}$ & $\begin{array}{c}0 \\
2 \\
2 \\
10 \\
10\end{array}$ \\
\hline SCK & $\begin{array}{c}\text { Stockton } \\
\text { Metropolitan } \\
\text { Airport }\end{array}$ & 9 & $\begin{array}{l}\text { Sea Level Pressure } \\
\text { Air Temperature } \\
\text { Relative Humidity } \\
\text { Wind Speed } \\
\text { Wind Direction }\end{array}$ & $\begin{array}{c}0 \\
2 \\
2 \\
10 \\
10\end{array}$ \\
\hline TRY & $\begin{array}{c}\text { Tracy Airport } \\
\text { CARB }\end{array}$ & 60 & $\begin{array}{c}\text { Sea Level Pressure } \\
\text { Air Temperature } \\
\text { Wind Speed } \\
\text { Wind Direction }\end{array}$ & $\begin{array}{c}0 \\
2 \\
10 \\
10\end{array}$ \\
\hline VAQ & $\begin{array}{c}\text { Vaquero } \\
\text { Reservoir } \\
\text { RAWS }\end{array}$ & 335 & $\begin{array}{l}\text { Air Temperature } \\
\text { Relative Humidity } \\
\text { Wind Speed } \\
\text { Wind Direction }\end{array}$ & $\begin{array}{c}2 \\
2 \\
10 \\
10\end{array}$ \\
\hline
\end{tabular}


TABLE 4. Station information for LLNL observation sites.

\begin{tabular}{|c|c|c|c|c|}
\hline $\begin{array}{c}\text { Station } \\
\text { ID }\end{array}$ & Station Name & $\begin{array}{c}\text { Station } \\
\text { Elev. } \\
(\mathrm{m})\end{array}$ & $\begin{array}{c}\text { Data } \\
\text { Available }\end{array}$ & $\begin{array}{c}\text { AGL Elev. } \\
\text { of Variable } \\
(\mathrm{m})\end{array}$ \\
\hline LNL & LLNL- & 174 & Sea Level Pressure & 0 \\
& Livermore & & Air Density & 10 \\
& & & Air Temperature & $2,10,23,52$ \\
& & & Relative Humidity & $2,10,23,52$ \\
& & & Air Pressure & $10,23,52$ \\
& & & Wind Speed & $10,23,52$ \\
& & & Wind Speed $\sigma$ & $10,23,52$ \\
& & Wind Direction & $10,23,52$ \\
\hline S3H & LLNL- & 387 & Sea Level Pressure & 0 \\
& Site 300 & & Surface Heat Flux & 0 \\
& & & Air Density & 10 \\
& & & Air Temperature & $2,10,23,52$ \\
& & & Relative Humidity & $2,10,23,52$ \\
& & & Air Pressure & $10,23,52$ \\
& & & Wind Speed & $10,23,52$ \\
& & & Wind Speed $\sigma$ & $10,23,52$ \\
& & & Wind Direction & $10,23,52$ \\
\hline
\end{tabular}

The traditional statistical measures used in model performance evaluation are mean absolute error,

$$
M A E=\frac{1}{n} \sum|F-A|
$$

root mean square error,

$$
R M S E=\sqrt{\frac{1}{n} \sum(F-A)^{2}}
$$

and anomaly correlation,

$$
A C C=\frac{n \sum F A-\sum F \sum A}{\sqrt{\left.\left[n \sum F^{2}-\left(\sum F\right)^{2}\right] n \sum A^{2}-\left(\sum A\right)^{2}\right]}},
$$

where $F$ represents the forecast value and $A$ represents the observed value (Reid and Turner 2001; Rife et al. 2004; Žagar et al. 2006; Jimenez et al. 2010). MAE and RMSE 
TABLE 5. Modeled Wind Speed Statistical Performance Grades.

\begin{tabular}{|c|c|c|c|}
\hline Grade & $\begin{array}{c}\text { MAE } \\
\left(\mathrm{m} \mathrm{s}^{-1}\right)\end{array}$ & $\begin{array}{c}\text { RMSE } \\
\left(\mathrm{m} \mathrm{s}^{-1}\right)\end{array}$ & $\begin{array}{c}\text { ACC } \\
\text { (unitless) }\end{array}$ \\
\hline Poor & $>3.0$ & $>3.0$ & $<0.50$ \\
\hline Acceptable & $<3.0$ & $<3.0$ & $>0.50$ \\
\hline Good & $<2.5$ & $<2.5$ & $>0.60$ \\
\hline Excellent & $<2.0$ & $<2.0$ & $>0.75$ \\
\hline
\end{tabular}

can vary significantly across a large geographic region and thus a threshold of acceptable predictability can be difficult to establish. However, MAE and RMSE values provide a range in which the different simulations can vary from observations for smaller geographic regions. For this analysis, WRF model performance for wind speed MAE and RMSE values under 3.0, 2.5, and $2.0 \mathrm{~m} \mathrm{~s}^{-1}$ are considered acceptable, good, and excellent, respectively (Table 5). ACC provides an apt matching standard across a model's entire domain no matter its geographic size. Although it is generally understood that correlations between simulated and observed flows are lowest in regions of highest terrain complexity, an ACC of 0.5 is the lowest threshold for an acceptable forecast (Reid and Turner 2001). For this analysis, WRF model performance for wind speed ACC values over $0.50,0.60$, and 0.75 are considered acceptable, good, and excellent, respectively (Table 5).

Statistical calculations were done for the whole 84-hour model run as well as individual 24-hour periods. Day One, Two, and Three statistical values represent the first, second, and third 24 hours of each model run, while Day Four statistical values represent the last 12 hours. While the accuracy of the entire 84 hour model run is important, Day One and Day Two model accuracy is much more critical for energy planning (Bathurst et al. 2002; Kariniotakis et al. 2004), and these results are highlighted. 


\section{Results and Discussion}

\section{a. Near-Surface Wind Field}

The five WRF model runs were evaluated against observations for the nearsurface wind field at the eleven sites listed in Tables 2 and 3. Model accuracy for 6 and $10 \mathrm{~m}$ AGL wind speed was evaluated using MAE, RMSE, and ACC (equations 8-10). The average 84-hour wind speed MAE was 2.5, 2.2, 2.2, 2.2, and $2.0 \mathrm{~m} \mathrm{~s}^{-1}$ for each of the five cases, respectively (Fig. 3). The average 84-hour wind speed RMSE was 2.9, 2.5, 2.6, 2.6, and $2.4 \mathrm{~m} \mathrm{~s}^{-1}$ for each of the five cases, respectively (Fig. 4). The average 84hour wind speed ACC was $0.45,0.58,0.60,0.50$, and 0.56 for each of the five cases, respectively (Fig. 5). Additional analysis of MAE reveals that the 84-hour, Day One, and Day Two wind speed MAEs were less than $2.0 \mathrm{~m} \mathrm{~s}^{-1}$ in 60,58 , and 56 percent of the instances, respectively (Fig. 3). The 84-hour, Day One, and Day Two wind speed MAEs were less than $2.5 \mathrm{~m} \mathrm{~s}^{-1}$ in 81,67 , and 72 percent of the instances, respectively. Furthermore, additional analysis of wind speed RMSE reveals the 84-hour, Day One, and Day Two wind speed RMSEs were less than $2.0 \mathrm{~m} \mathrm{~s}^{-1}$ in 42,36 , and 45 percent of the instances, respectively (Fig. 4). The 84-hour, Day One, and Day Two wind speed RMSE were less than $2.5 \mathrm{~m} \mathrm{~s}^{-1}$ in 66,43 , and 63 percent of the instances, respectively. WRF-modeled wind direction was evaluated for the same eleven comparison sites. Over the five cases simulated, WRF-modeled and observed wind directions were in good agreement (Fig. 6). Interestingly, the LTR, VAQ, and AAT sites, which are all located in the most complex terrain of the eleven comparison sites, exhibited the highest 

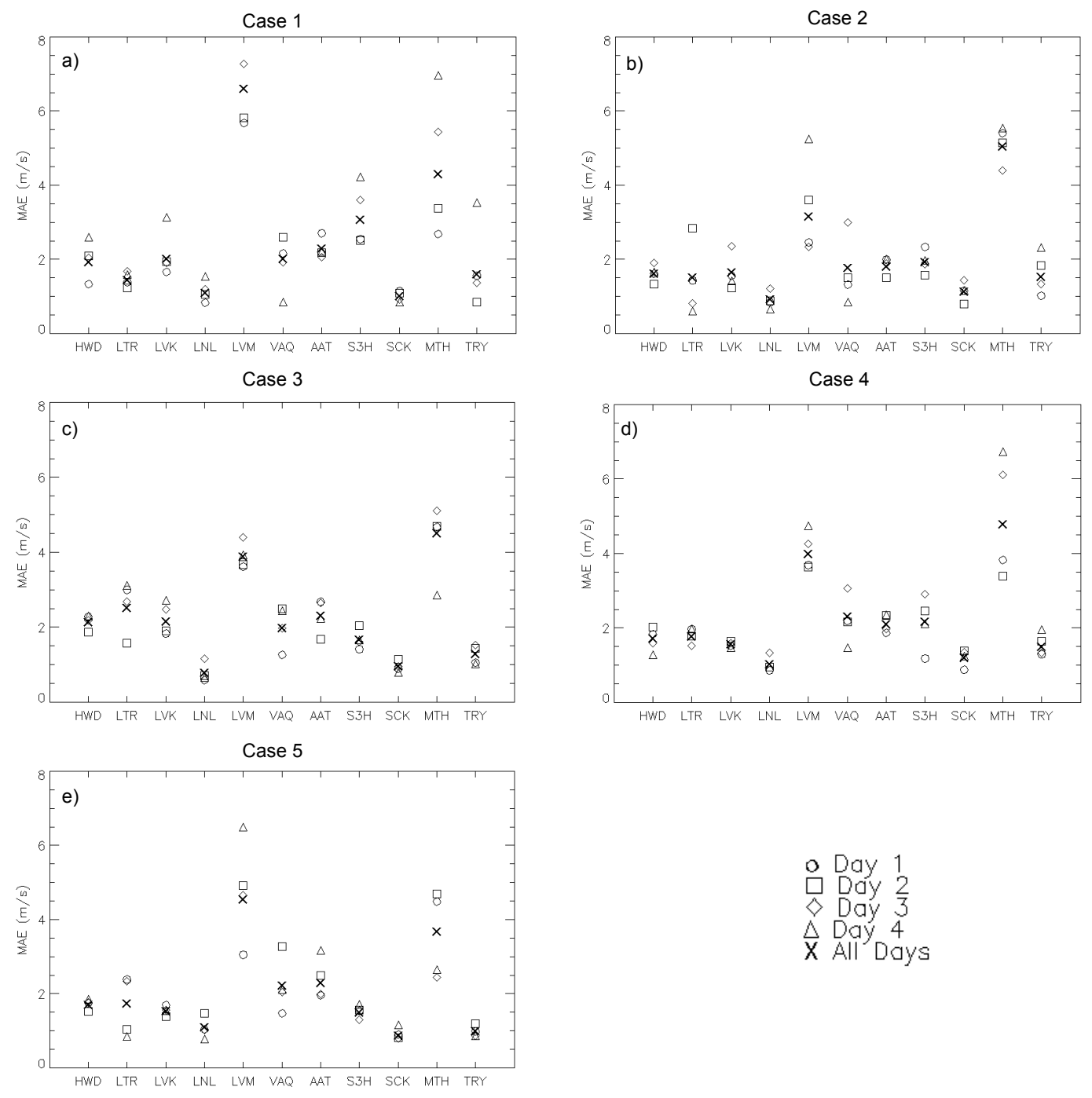

FIG. 3. Wind speed MAE statistic plots for the five LSMF case studies at the eleven near-surface flow observation sites.

agreements. This may be due to terrain channeling and thermally driven circulations through Altamont Pass, making the wind direction less variable compared to sites in relatively flat terrain.

Analysis of WRF-modeled temperature, relative humidity, and sea-level pressure over all five cases, yield ACCs results of over 0.70, 0.60, and 0.65, respectively. 

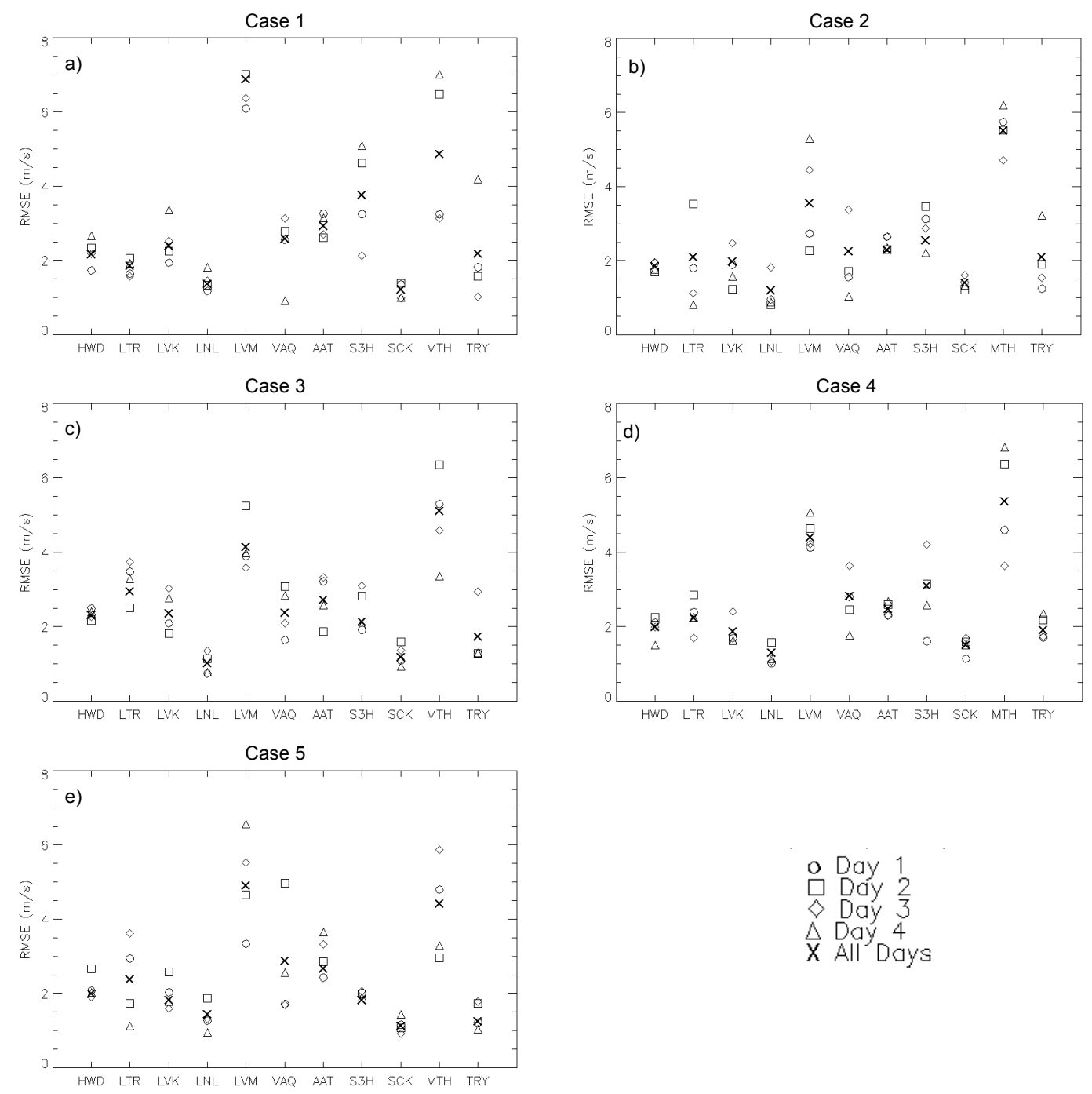

FIG. 4. Wind speed RMSE statistic plots for the five LSMF case studies at the eleven near-surface flow observation sites.

Additionally, over the five cases, MAE results were near $2.0 \mathrm{~K}, 10$ percent, and $2 \mathrm{hPa}$ for temperature, relative humidity and surface pressure respectively; while RMSE results were near $2.5 \mathrm{~K}, 12$ percent, and $2.5 \mathrm{hPa}$, respectively (not shown).

Over all five cases, WRF performance was best at LNL and SCK, with low wind speed MAEs and RMSEs, and high ACCs. This is to be expected as both sites are 

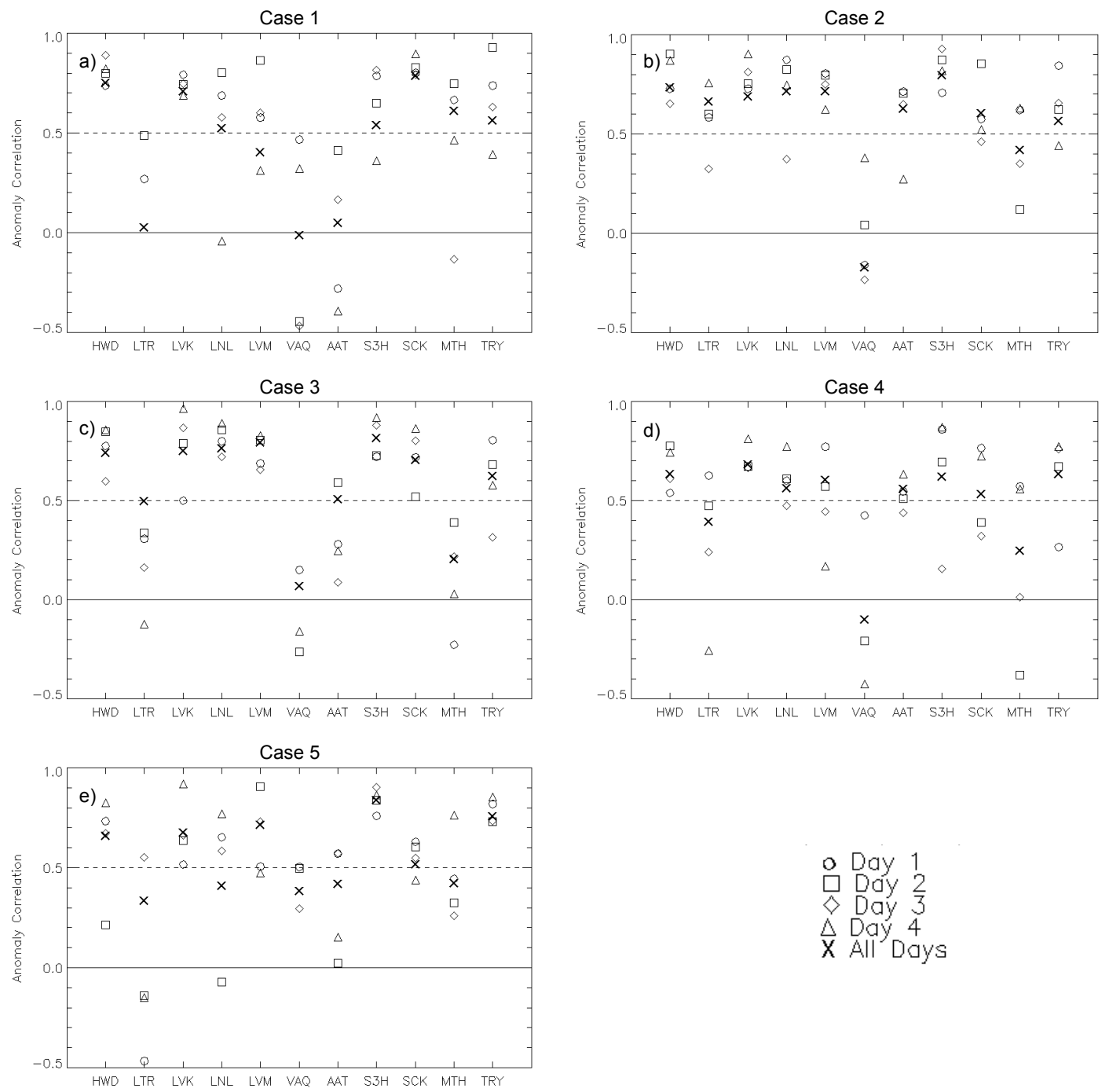

FIG. 5. Wind speed ACC statistic plots for the five LSMF case studies at the eleven near-surface flow observation sites.

located in flat, non-complex terrain; however, given their locations west and east of Altamont Pass, their model accuracy is quite beneficial. Highly accurate wind speed, wind direction, temperature, and pressure gradient forecasts across the pass could possibly be used in future regional wind and wind power forecasts. 

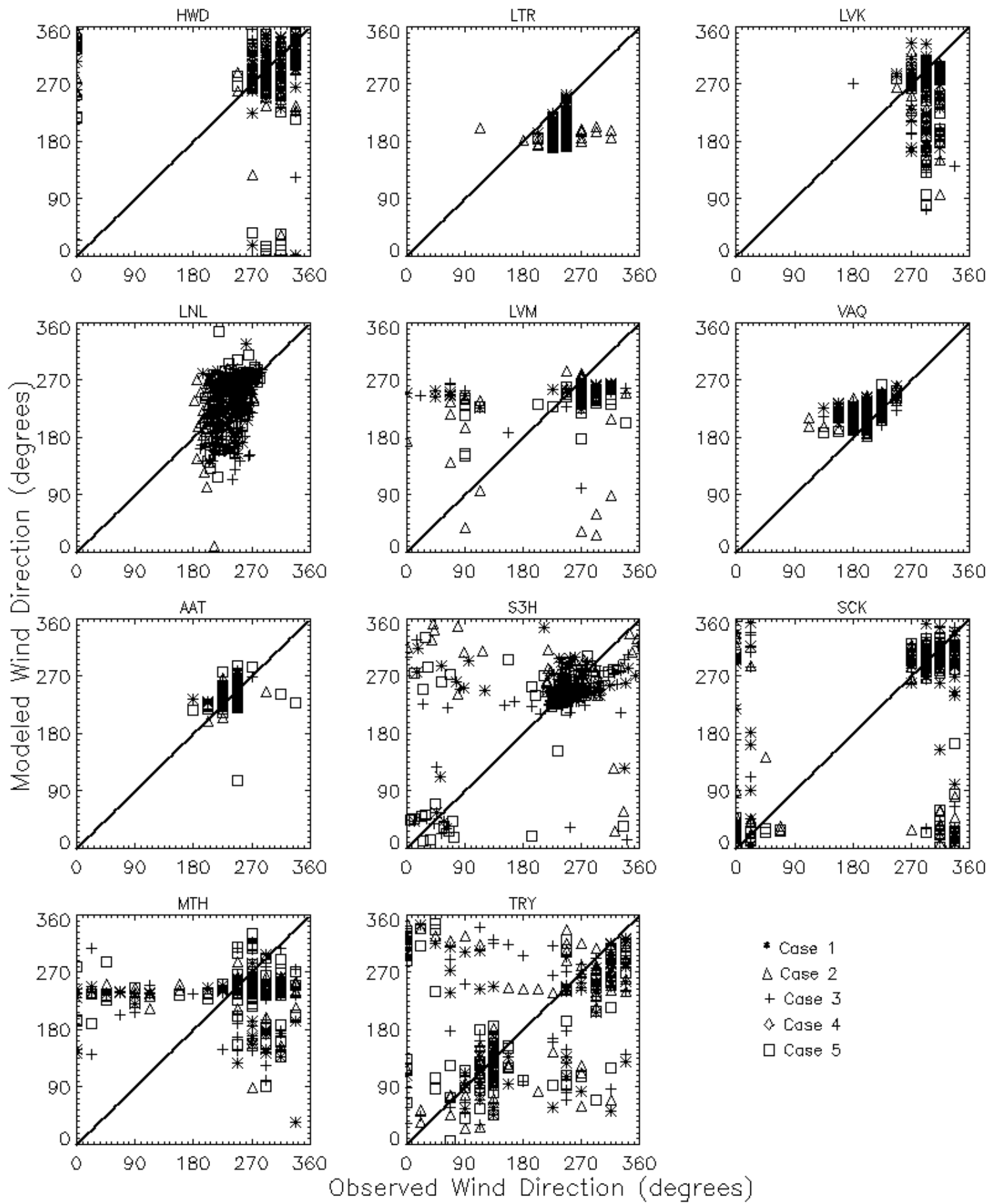

FIG. 6. Modeled versus observed wind direction for the five LSMF case studies at the eleven near-surface flow observation sites 
Over all five cases, WRF performance was the poorest at sites LVM and MTH, with high wind speed MAEs, RMSEs, and low ACCs. Possible explanations for the poor model performance at these sites can be linked to their location. The LVM meteorological tower is atop a very exposed ridgeline that can be subject to sporadic wind gusts and rapidly changing wind directions. These can be difficult to model in terms of intensity and timing. This result disagrees with the Žagar et al. (2006) findings that suggest ridgeline locations are better modeled when compared to other locales within complex terrain.

The MTH meteorological tower is located immediately downwind of Altamont Pass, and it is possible that when highly stable air crosses the pass, a hydraulic jump occurs in the lee near MTH. If WRF does not resolve the location of the hydraulic jump perfectly, then correlations between modeled and observed conditions suffer. It appears WRF did not accurately simulate these sporadic wind variations at these two locations, leading to poor statistical performance at these sites.

While model accuracy is linked to terrain complexity, WRF performance was not greatly degraded at those sites in highly complex terrain. WRF-modeled winds at the VAQ and AAT sites, which are at the northern and southern ends of Altamont Pass, show acceptable to good performance. AAT wind speed ACC fluctuated above and below the level of acceptable correlation, while VAQ wind speed ACC was typically near 0.0 for all five cases. However, AAT and VAQ exhibited wind speed MAE and RMSE values similar to the other comparison sites in much less complex terrain. In addition, WRFmodeled and observed wind directions were in very good agreement at these comparison 
sites. While modeled hour-to-hour variance was not exact, WRF-modeled wind speeds were similar to those observed, with accurate wind direction simulation. In summation, WRF performance was good for the near-surface wind field simulation.

\section{b. Altamont Pass Wind Field}

Statistical analysis of hub-height winds in Altamont Pass was performed for the six Areas in Fig. 2. At these sites, the average 84-hour wind speed MAE was 2.7, 2.5, 2.7, 2.3 and $2.4 \mathrm{~m} \mathrm{~s}^{-1}$ for each of the five cases, respectively (Fig. 7a, d, g, j, and m). The average 84-hour wind speed RMSE was 3.3, 3.1, 3.3, 3.3 and $2.9 \mathrm{~m} \mathrm{~s}^{-1}$ for each of the five cases, respectively (Fig. 7b, e, h, k, and n). The average 84-hour wind speed ACC for Areas 1 and 2 was $-0.10,0.28,0.45,0.45$, and 0.49 for each of the five cases, respectively (Fig. 7c, f, i, 1, and o); while the average 84-hour wind speed ACC for Areas 3 through 6 was $0.58,0.57,0.66,0.45$, and 0.65 for each of the five cases, respectively (Fig. 7c, f, i, 1, and o).

Across all six Areas for all five cases, the Day One and Day Two wind speed MAEs were less than the 84-hour wind speed MAE in 60 and 57 percent of the instances, respectively. Day One wind speed MAEs were less than $2.0,2.5$, and $3.0 \mathrm{~m} \mathrm{~s}^{-1}$ in 37,57 , and 87 percent of the instances, respectively. Day Two wind speed MAEs were less than 2.0, 2.5, and $3.0 \mathrm{~m} \mathrm{~s}^{-1}$ in 20,53 , and 67 percent of the instances, respectively. The Day One and Day Two wind speed RMSEs were less than the 84-hour wind speed RMSE in 60 and 47 percent of the instances, respectively. Day One wind speed RMSEs were less than $2.0,2.5$, and $3.0 \mathrm{~m} \mathrm{~s}^{-1}$ in 17,47 , and 70 percent of the instances, respectively. Day 

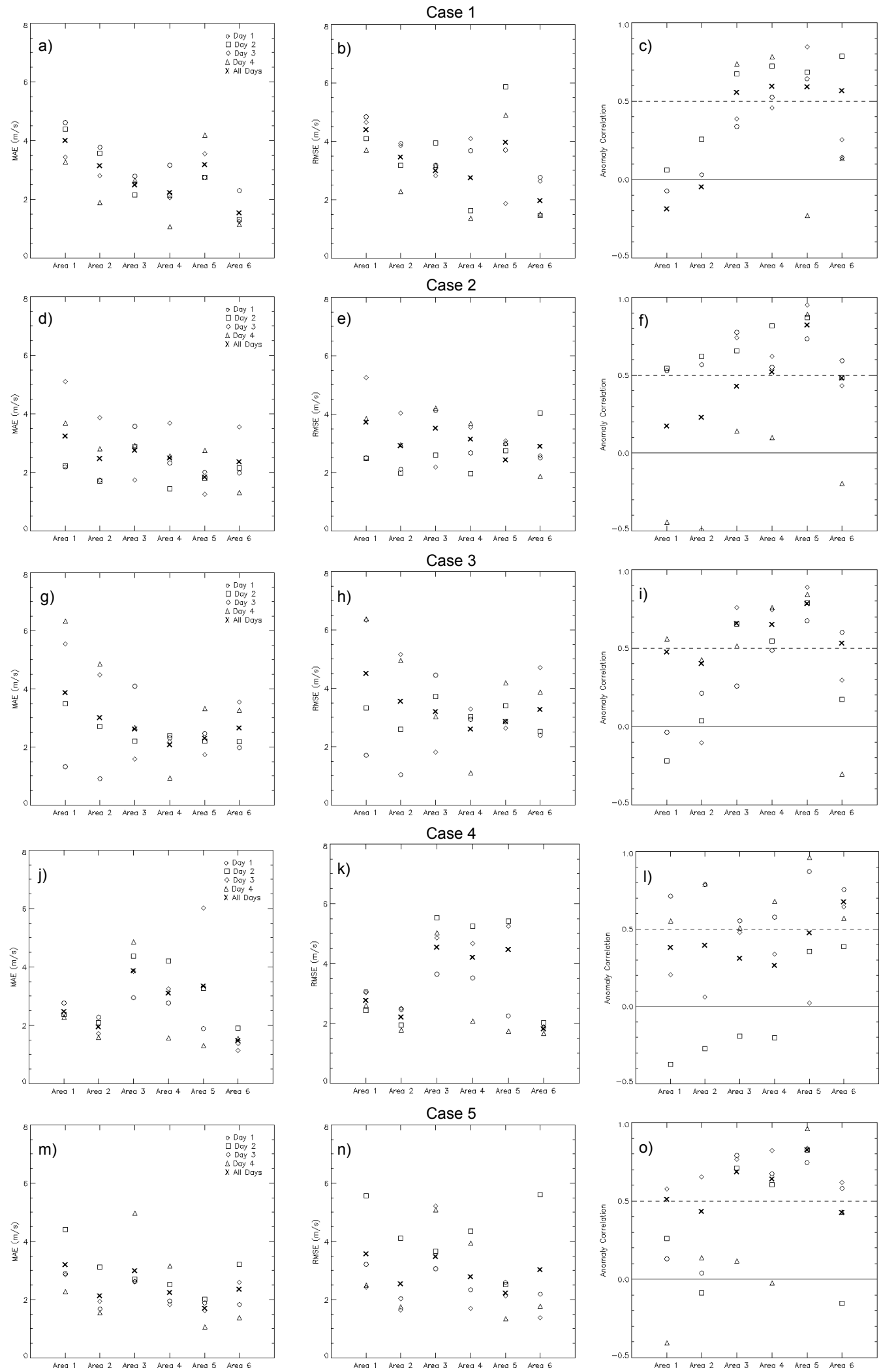

FIG. 7. Hub-height wind speed MAE, RMSE, and ACC performance for the five LSMF case studies at the six Altamont Pass observation areas. 

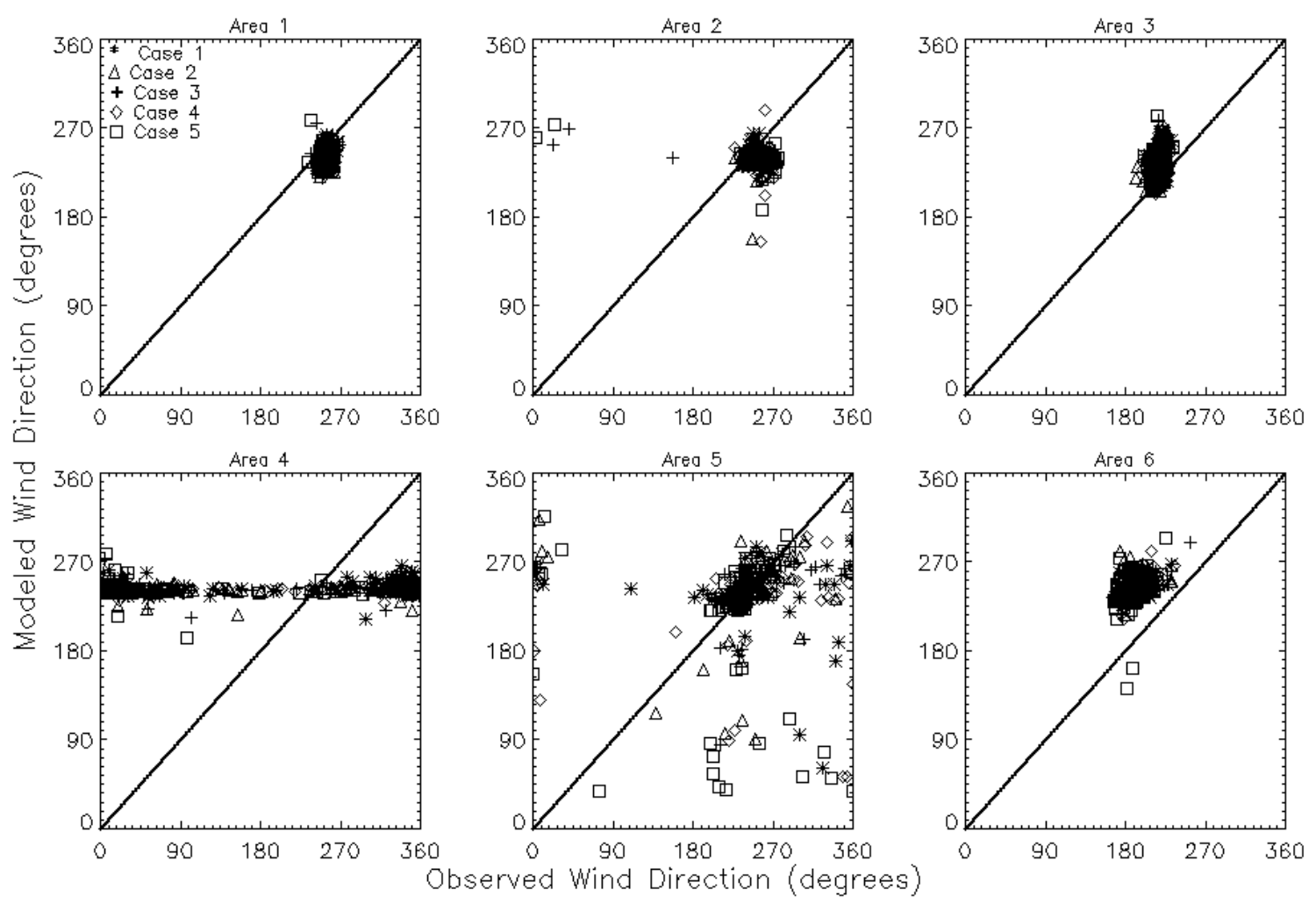

FIG. 8. Modeled versus observed hub-height wind direction for the five LSMF case studies at the six Altamont Pass observation areas.

Two wind speed RMSEs were less than 2.0, 2.5, and $3.0 \mathrm{~m} \mathrm{~s}^{-1}$ in 20,37 , and 47 percent of the instances, respectively. Excluding Areas 1 and 2, the Day One and Day Two wind speed ACCs were above 0.5 in 75 percent of the instances. While in several of the cases, the 84-hour wind speed ACC for several Areas was below the acceptable threshold, Day One and Day Two wind speed ACCs were above 0.5 in 66 and 33 percent of the instances, respectively. For those cases whose 84 -hour wind speed ACC was above the acceptable threshold, Day One and Day Two had a wind speed ACC at or above the 84hour ACC in 47 and 80 percent of the instances, respectively. 

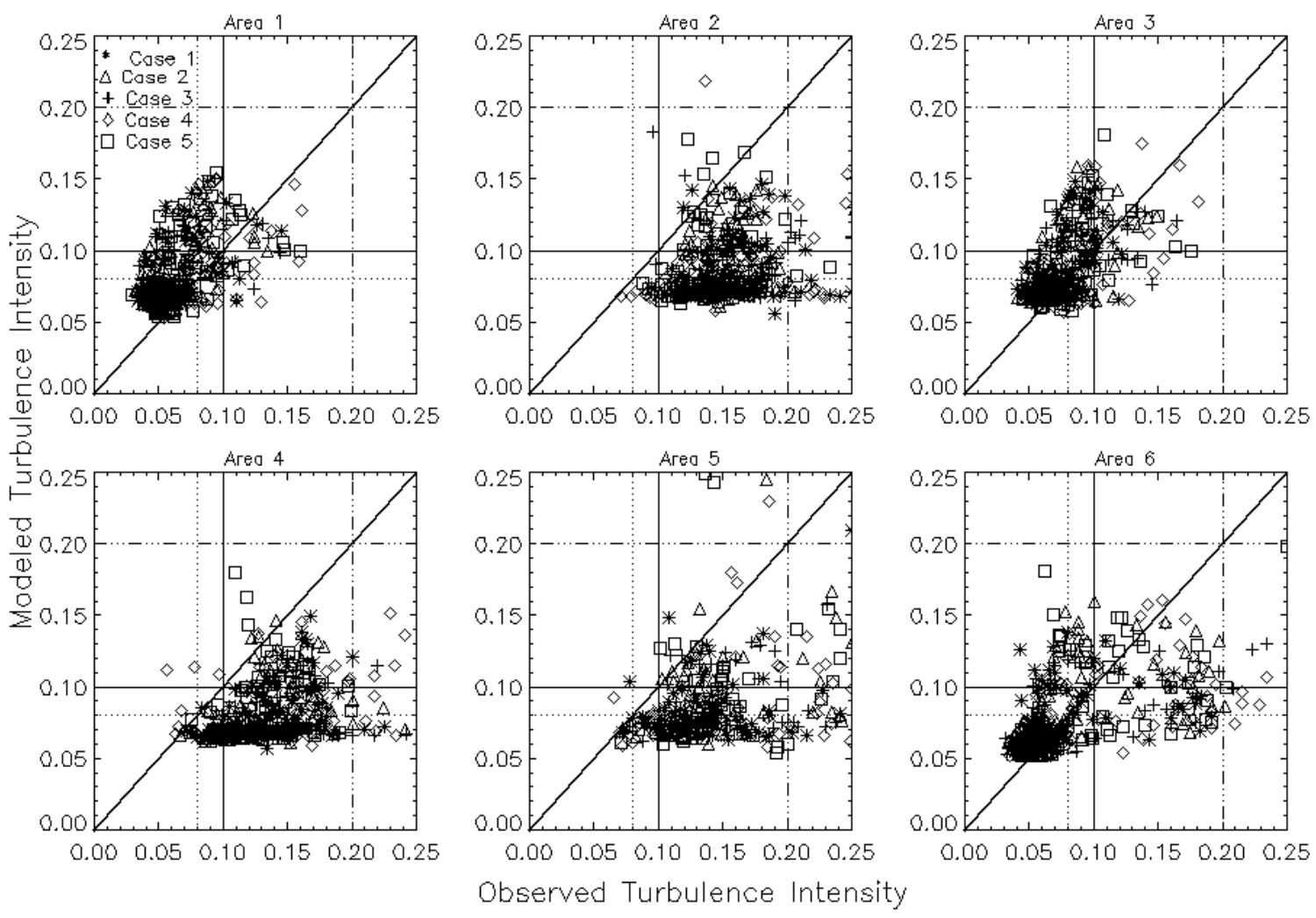

FIG. 9. Modeled versus observed turbulence intensity for the five LSMF case studies at the six Altamont Pass observation areas. Horizontal and vertical lines indicate stable (dotted), neutral (solid), and convective (dash-dotted) atmospheric conditions.

WRF-modeled and observed wind directions were in very good agreement at five of the six Areas (Fig. 8). WRF simulated wind direction predominantly fell within a W to SW range, with an average of WSW. Observed wind direction predominantly came from $\mathrm{W}$ to $\mathrm{SW}$, with an average of WSW. WRF also simulated the same W to SW wind direction range for Area 4. However, observations show winds almost equally from all directions, with some favoring of the NW to NE directions. After further investigation, it was determined that the local terrain and nearby wind turbines create some wrap around effects, skewing the recorded wind direction. These types of errors are not adjustable in 
the WRF model. Because of this it is believed that Area 3 wind direction could be used as proxy for Area 4.

WRF-modeled $T K E$ was converted to $I_{U}$ using equation (6) to compare against observed $I_{U}$ recorded at the six Altamont Pass Areas (Fig. 9). Following the stability classes assigned to $I_{U}$ values (Table 1), WRF simulations have a tendency towards strongly stable to slightly neutral conditions $\left(0.05<I_{U}<0.12\right)$ for all Areas, while observed atmospheric stability varied for each Area. For Areas 1, 3, and 6, observations were in good agreement with WRF, as they typically experienced strongly-stable to stable conditions $\left(0.04<I_{U}<0.10\right)$. In Areas 2, 4, and 5, stable to neutral conditions $\left(0.08<I_{U}<0.18\right)$ were much more prevalent.

Over all five cases, WRF-modeled wind speed exhibited the highest agreement with observations at Area 5. The 84-hour, Day One, and Day Two wind speed ACCs were all above 0.6 in four of the cases, two of which were above 0.75 . Area 5 MAE and RMSE were also consistently near or below the 84-hour case average. A possible explanation for good model performance in this location is its very close proximity to a WRF model grid point, resulting in very little point interpolation representativeness error. Additionally, WRF-modeled wind speed statistical performance at Areas 3, 4, and 6 were good as well. Combined with good agreement between both modeled and observed wind direction and atmospheric stability, the good to excellent model performance at these four Areas are promising for a future wind forecasting.

Over all five cases, Areas 1 and 2 consistently exhibited the lowest ACCs. However, Areas 1 and 2 showed very good agreement between modeled and observed 
wind direction and $I_{U}$ (Fig. 8 and 9). Furthermore, their wind speed MAEs and RMSEs were near the case average and in some instances lower (Fig. 7). Located at the western front of Altamont Pass where local topography is the steepest, WRF slightly smoothes out the terrain and therefore characterizes the hub-height above ground level at a lower elevation. While the hour-to-hour variance might not be well simulated at Areas 1 and 2, WRF-modeled winds were similar to those observed.

It is also worth mentioning that Day Three and Day Four WRF performance was generally acceptable to good (Fig. 7). While not as accurate as Day One and Day Two, WRF-modeled winds during this time period generally were within an acceptable range of the observed conditions. Therefore, their solutions could be used for forecasts longer in range than 48 hours. In summation, WRF performance for wind simulations at the Altamont Pass Areas 1 and 2 were acceptable.

\section{c. Wind Power Modeling}

WRF-modeled winds and TKE were used to determine wind power production in Altamont Pass. Equations (4), (5), and (6) were used to determine rotor area equivalent wind speeds, and equations (1) and (7) were used to determine the capacity factor (CF). A typical LSMF day for Altamont Pass winds and wind power are shown in Figs. 10-17. The series begins on 24 July 1100 local time (LT), and ends 25 July 1100 LT, and exhibits an average Froude number of 1.03, with a Froude number slightly less than 1.0 during the evening and night hours. WRF-modeled and observed winds across the Altamont Pass region during this time frame are in good to excellent agreement, with a MAE of $2.4 \mathrm{~m} \mathrm{~s}^{-1}$, a RMSE of $2.8 \mathrm{~m} \mathrm{~s}^{-1}$ and an ACC of 0.74 (not shown). 

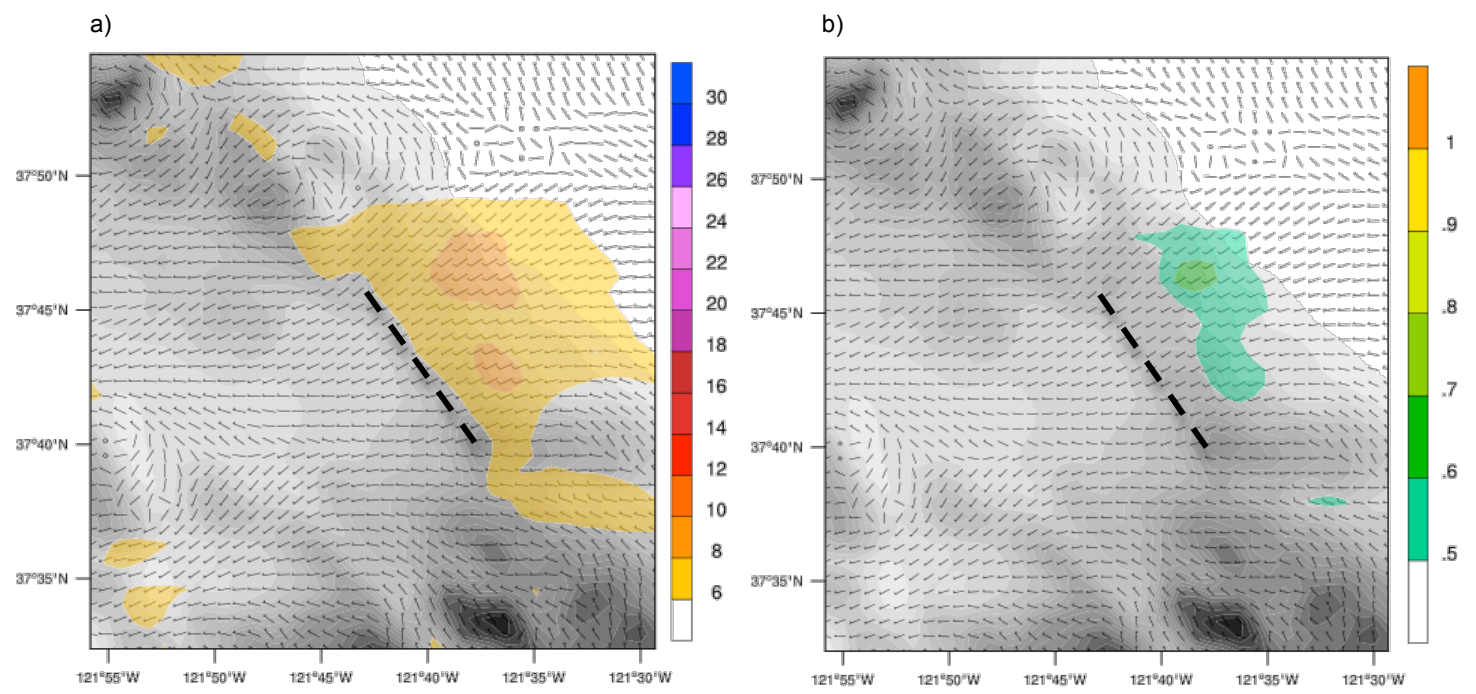

FIG. 10. WRF-modeled near surface flow in Altamont Pass, 1100 LT 24 July 2010. Elevation contoured every $100 \mathrm{~m}$ starting at $0 \mathrm{~m}$ MSL (white). (a) Hub-height equivalent winds. Wind barbs, $10 \mathrm{~m} \mathrm{~s}^{-1}$; half barb, $5 \mathrm{~m} \mathrm{~s}^{-1}$. Winds $\geq 6 \mathrm{~m} \mathrm{~s}^{-1}$ are shaded in increments of $2 \mathrm{~m} \mathrm{~s}^{-1}$. (b) Hub-height CF. CFs $\geq 0.5$ are shaded in increments of 0.1. Dashed line marks location of the western edge of the Altamont Pass ridgeline.

a)

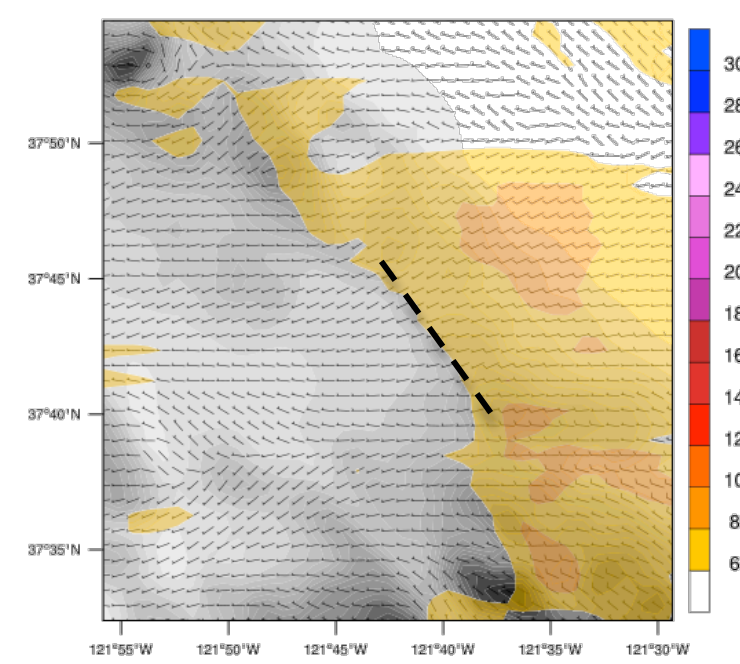

b)

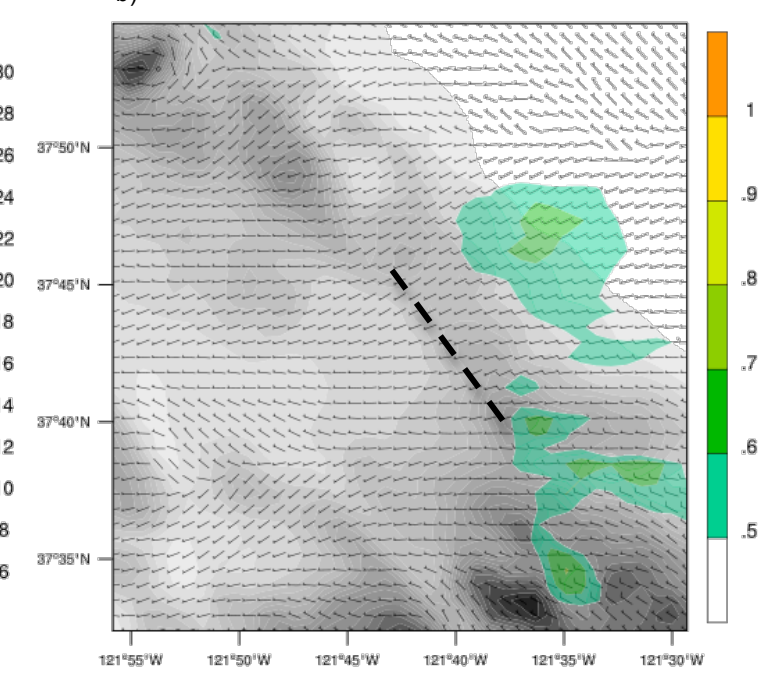

FIG. 11. WRF-modeled near surface flow in Altamont Pass, 1400 LT 24 July 2010. Elevation contoured every $100 \mathrm{~m}$ starting at $0 \mathrm{~m}$ MSL (white). (a) Hub-height equivalent winds. Wind barbs, $10 \mathrm{~m} \mathrm{~s}^{-1}$; half barb, $5 \mathrm{~m} \mathrm{~s}^{-1}$. Winds $\geq 6 \mathrm{~m} \mathrm{~s}^{-1}$ are shaded in increments of $2 \mathrm{~m} \mathrm{~s}^{-1}$. (b) Hub-height CF. CFs $\geq 0.5$ are shaded in increments of 0.1. Dashed line marks location of the western edge of the Altamont Pass ridgeline. 
a)

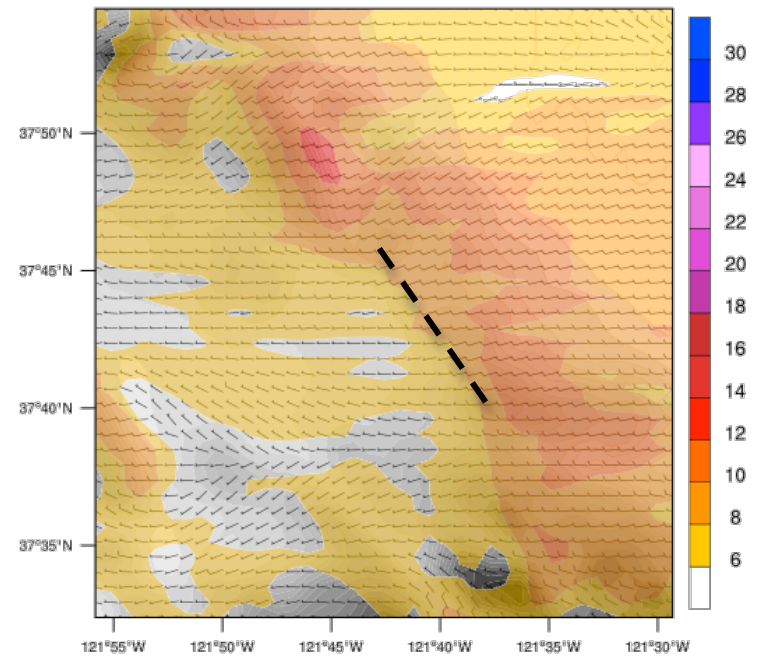

b)

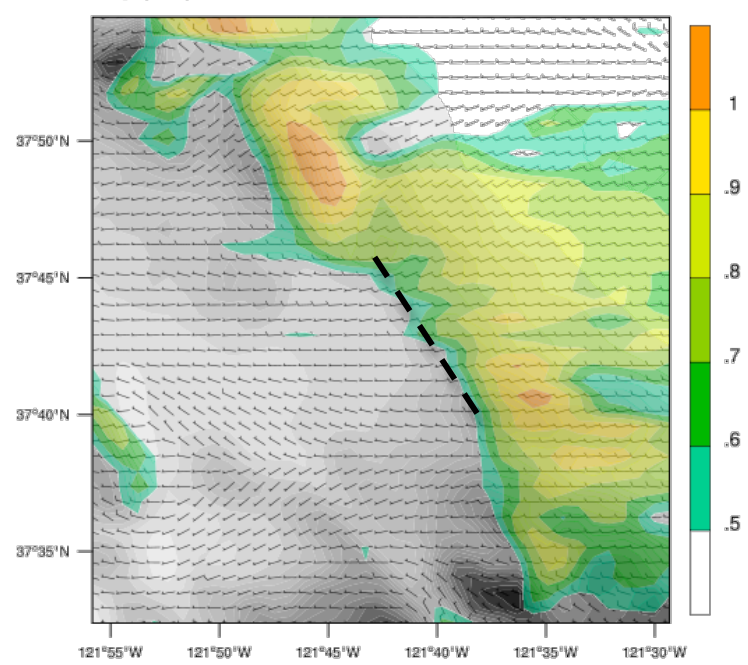

FIG. 12. WRF-modeled near surface flow in Altamont Pass, 1700 LT 24 July 2010. Elevation contoured every $100 \mathrm{~m}$ starting at $0 \mathrm{~m}$ MSL (white). (a) Hub-height equivalent winds. Wind barbs, $10 \mathrm{~m} \mathrm{~s}^{-1}$; half barb, $5 \mathrm{~m} \mathrm{~s}^{-1}$. Winds $\geq 6 \mathrm{~m} \mathrm{~s}^{-1}$ are shaded in increments of $2 \mathrm{~m} \mathrm{~s}^{-1}$. (b) Hub-height CF. CFs $\geq 0.5$ are shaded in increments of 0.1. Dashed line marks location of the western edge of the Altamont Pass ridgeline.

a)

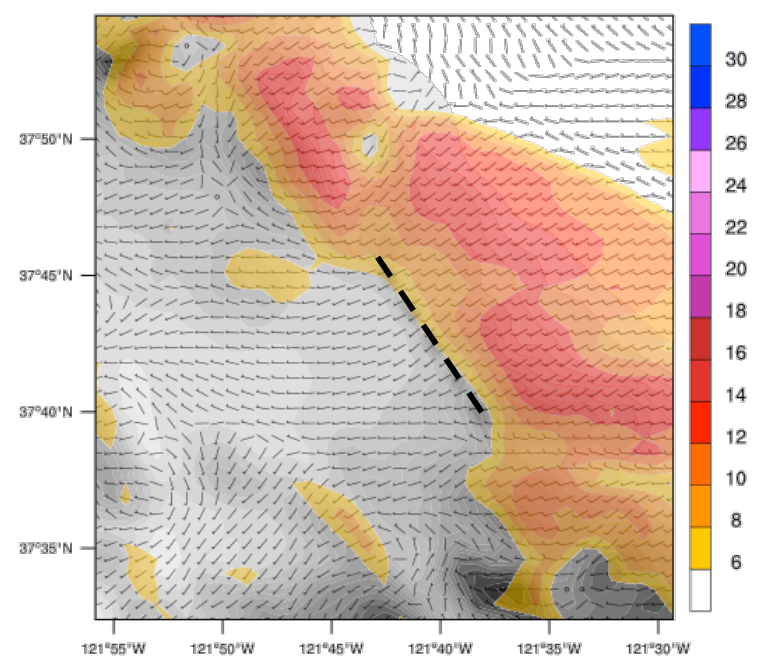

b)

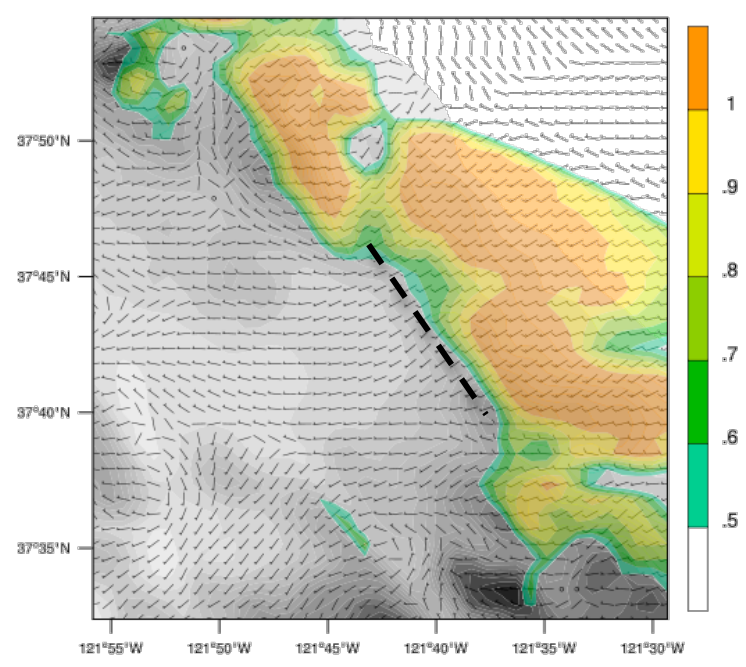

Fig. 13. WRF-modeled near surface flow in Altamont Pass, 2000 LT 24 July 2010. Elevation contoured every $100 \mathrm{~m}$ starting at $0 \mathrm{~m}$ MSL (white). (a) Hub-height equivalent winds. Wind barbs, $10 \mathrm{~m} \mathrm{~s}^{-1}$; half barb, $5 \mathrm{~m} \mathrm{~s}^{-1}$. Winds $\geq 6 \mathrm{~m} \mathrm{~s}^{-1}$ are shaded in increments of $2 \mathrm{~m} \mathrm{~s}^{-1}$. (b) Hub-height CF. CFs $\geq 0.5$ are shaded in increments of 0.1. Dashed line marks location of the western edge of the Altamont Pass ridgeline. 
a)

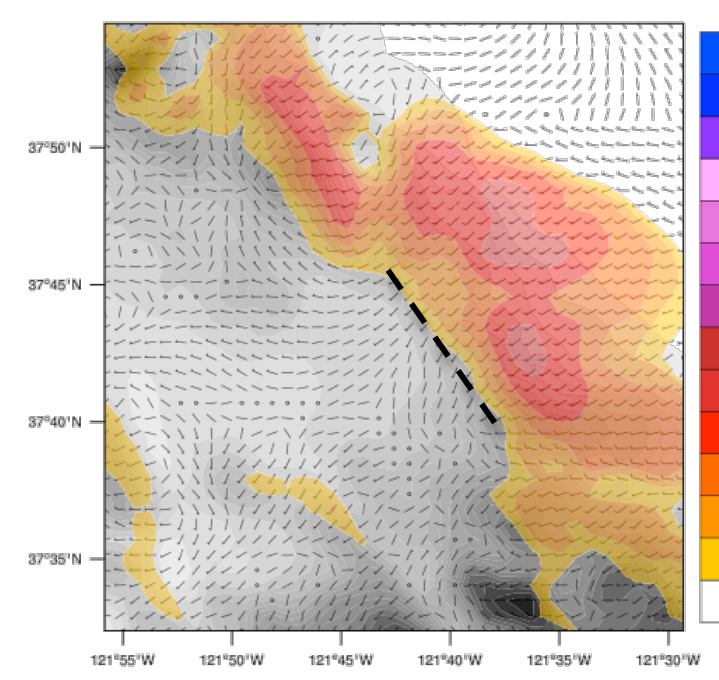

b)

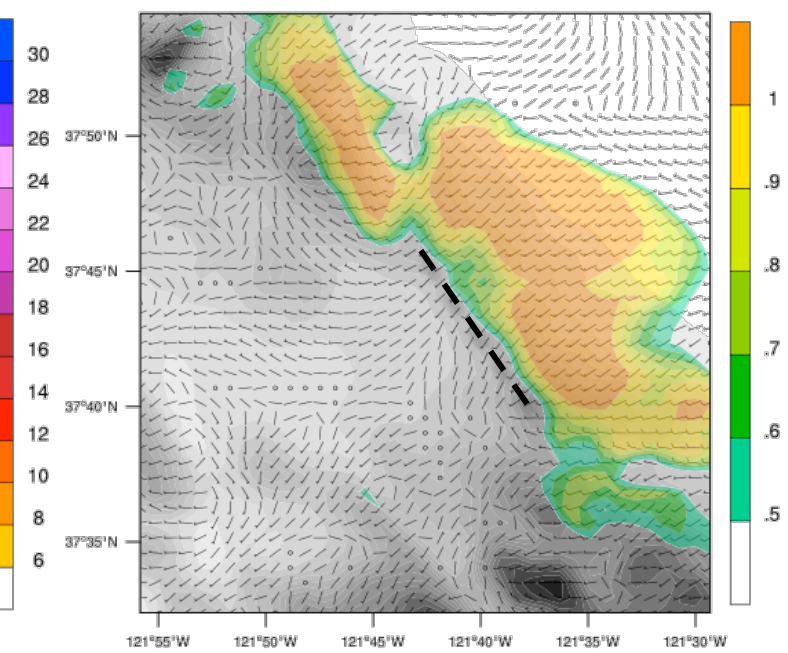

FIG. 14. WRF-modeled near surface flow in Altamont Pass, 2300 LT 24 July 2010. Elevation contoured every $100 \mathrm{~m}$ starting at $0 \mathrm{~m}$ MSL (white). (a) Hub-height equivalent winds. Wind barbs, $10 \mathrm{~m} \mathrm{~s}^{-1}$; half barb, $5 \mathrm{~m} \mathrm{~s}^{-1}$. Winds $\geq 6 \mathrm{~m} \mathrm{~s}^{-1}$ are shaded in increments of $2 \mathrm{~m} \mathrm{~s}^{-1}$. (b) Hub-height CF. CFs $\geq 0.5$ are shaded in increments of 0.1. Dashed line marks location of the western edge of the Altamont Pass ridgeline.

a)

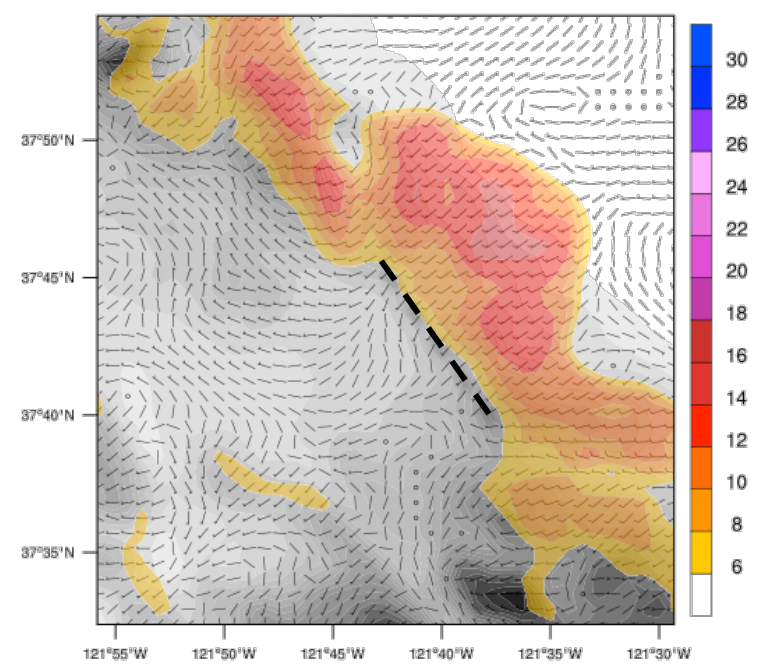

b)

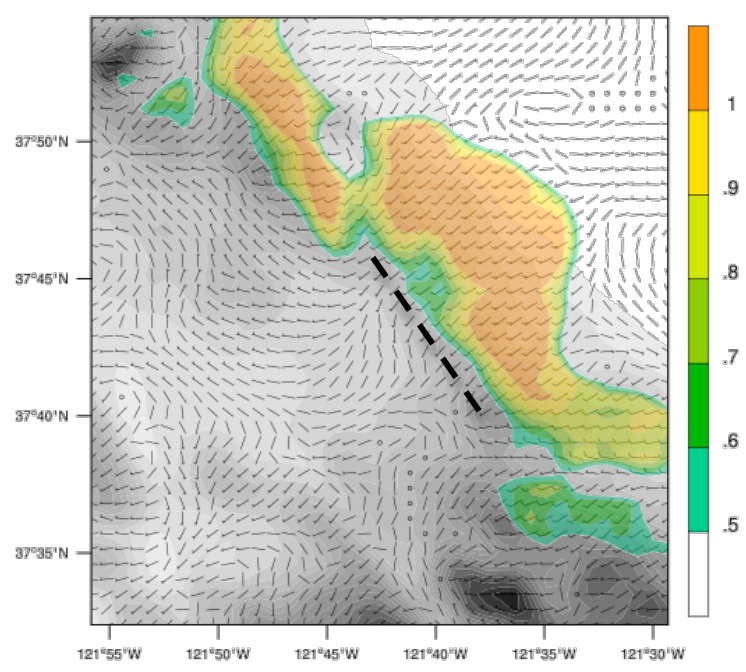

FIG. 15. WRF-modeled near surface flow in Altamont Pass, 0200 LT 25 July 2010. Elevation contoured every $100 \mathrm{~m}$ starting at $0 \mathrm{~m}$ MSL (white). (a) Hub-height equivalent winds. Wind barbs, $10 \mathrm{~m} \mathrm{~s}^{-1}$; half barb, $5 \mathrm{~m} \mathrm{~s}^{-1}$. Winds $\geq 6 \mathrm{~m} \mathrm{~s}^{-1}$ are shaded in increments of $2 \mathrm{~m} \mathrm{~s}^{-1}$. (b) Hub-height CF. CFs $\geq 0.5$ are shaded in increments of 0.1. Dashed line marks location of the western edge of the Altamont Pass ridgeline. 

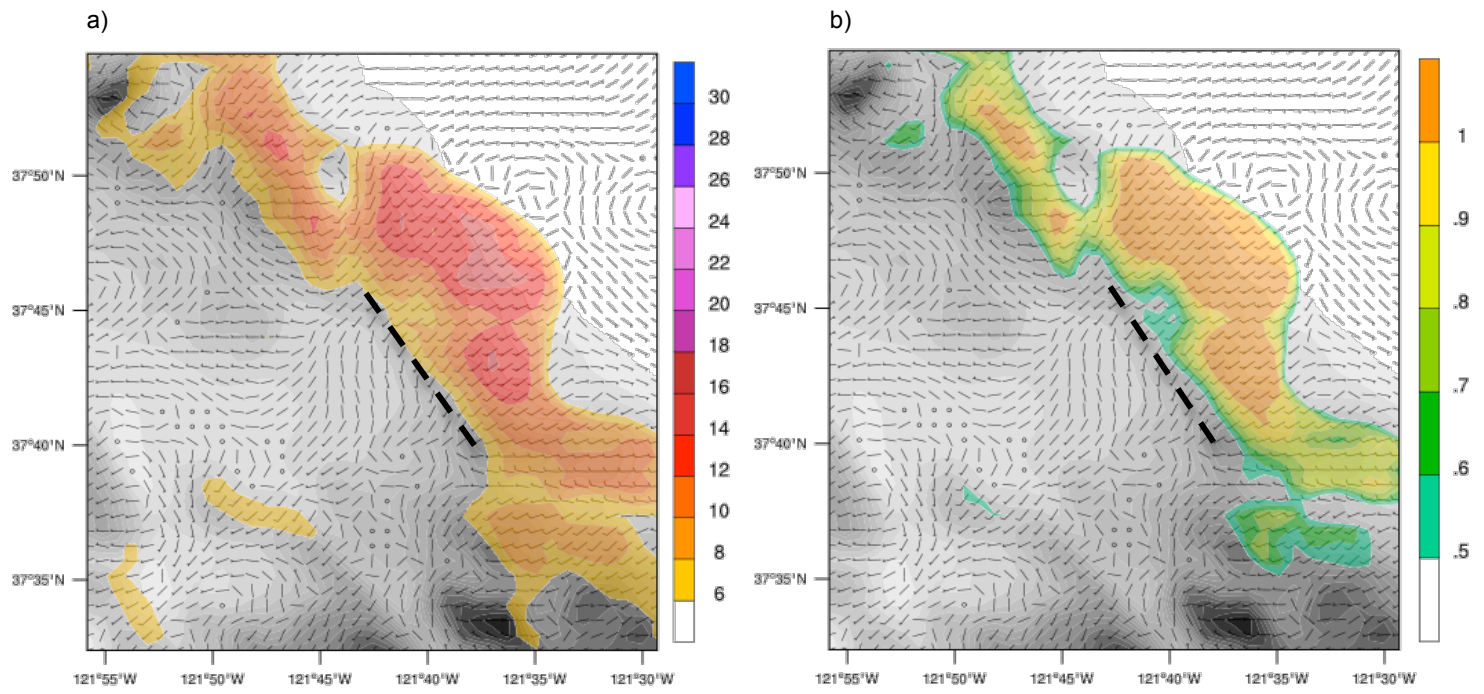

FIG. 16. WRF-modeled near surface flow in Altamont Pass, 0500 LT 25 July 2010. Elevation contoured every $100 \mathrm{~m}$ starting at $0 \mathrm{~m}$ MSL (white). (a) Hub-height equivalent winds. Wind barbs, $10 \mathrm{~m} \mathrm{~s}^{-1}$; half barb, $5 \mathrm{~m} \mathrm{~s}^{-1}$. Winds $\geq 6 \mathrm{~m} \mathrm{~s}^{-1}$ are shaded in increments of $2 \mathrm{~m} \mathrm{~s}^{-1}$. (b) Hub-height CF. CFs $\geq 0.5$ are shaded in increments of 0.1. Dashed line marks location of the western edge of the Altamont Pass ridgeline.

a)

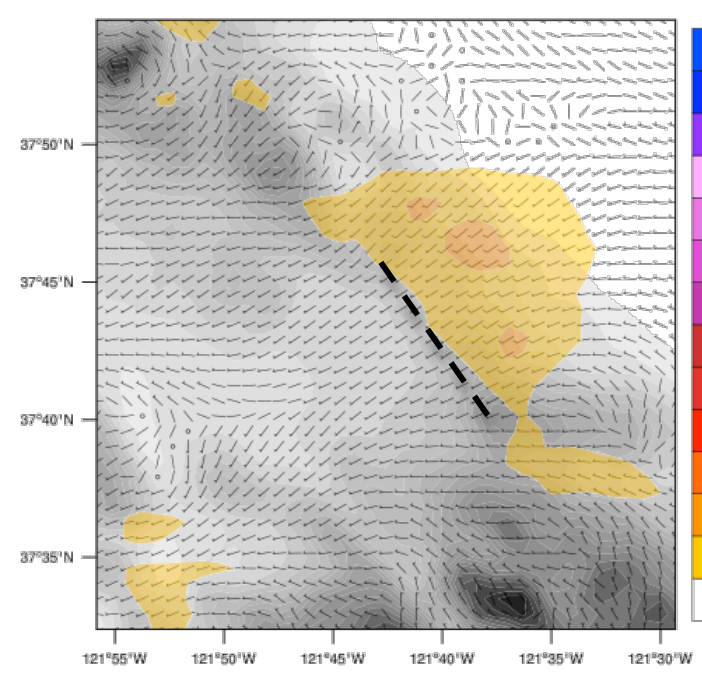

b)

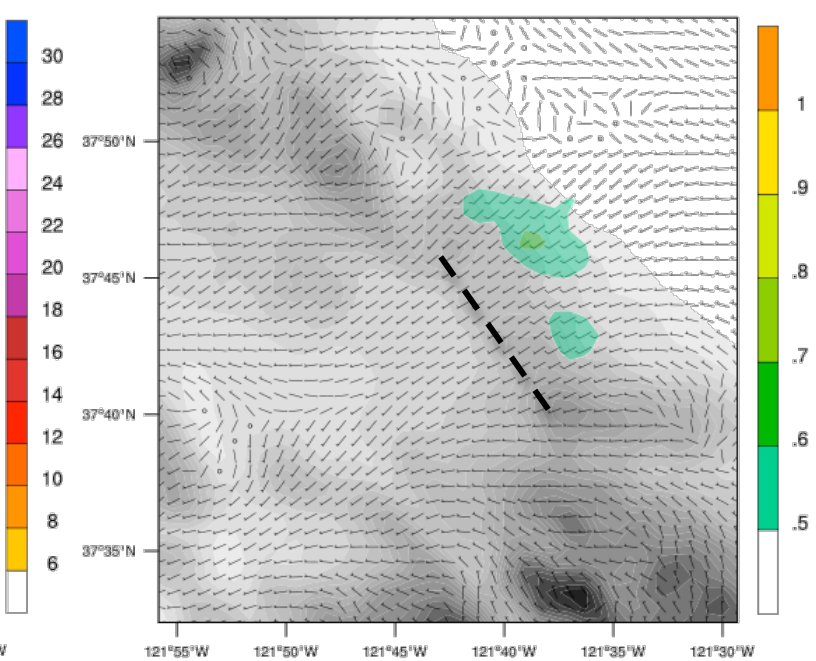

FIG. 17. WRF-modeled near surface flow in Altamont Pass, 1100 LT 25 July 2010. Elevation contoured every $100 \mathrm{~m}$ starting at $0 \mathrm{~m}$ MSL (white). (a) Hub-height equivalent winds. Wind barbs, $10 \mathrm{~m} \mathrm{~s}^{-1}$; half barb, $5 \mathrm{~m} \mathrm{~s}^{-1}$. Winds $\geq 6 \mathrm{~m} \mathrm{~s}^{-1}$ are shaded in increments of $2 \mathrm{~m} \mathrm{~s}^{-1}$. (b) Hub-height CF. CFs $\geq 0.5$ are shaded in increments of 0.1. Dashed line marks location of the western edge of the Altamont Pass ridgeline. 
Winds decrease through the morning hours before reaching a minimum in the early afternoon (1300 LT), with a similar decrease in CF as regional values drop below 0.50 (Figs. 10 and 11). By $1700 \mathrm{LT}$ winds increase by $2-5 \mathrm{~m} \mathrm{~s}^{-1}$, resulting in an increase in CF of 0.2-0.3 (Fig. 12). The greatest increases in winds through Altamont Pass occur between 1700 and 2000 LT when regional winds are up to $15 \mathrm{~m} \mathrm{~s}^{-1}$ after an additional 4-6 $\mathrm{m} \mathrm{s}^{-1}$ increase (Fig. 13). Wind power ramps during this period with most of Altamont Pass within a CF of 0.9 or greater and a large area achieving a CF of 1.0 (Fig. 13). Wind speed and wind power peak near 2300 LT before decreasing through the late night and early morning hours (Figs. 14 and 15). By 0200 LT, wind speeds are similar in strength to the 2000 LT winds and continue to decrease through the morning hours until winds are again light at 1100 LT the following day (Figs. 15-17). Wind power follows a similar trend during this period. In total, WRF model results show Altamont Pass in a CF of 0.5 or greater for 16 hours of a LSMF day with at least six of the hours, during the late afternoon into evening, achieving a near optimal CF.

Wind directions through Altamont Pass remain relatively constant (Figs. 10-17). The NW to W wind directions upwind consistently turn to WSW as they cross the pass before typically turning back W to NW direction in the downwind Central Valley, regardless of the exact surface pressure gradient orientation.

Due to the hilly bottom of Altamont Pass, flow enhancements such as vertical compression of air over a ridge, gap flow acceleration, and atmospheric wave formation can occur in combination during LMSF synoptic conditions, resulting in high levels of available wind power. Given a modeled Froude number near and slightly below 1.0, it 
appears WRF models these enhancements as it simulates an area of accelerated wind speed from the pass crest extending to the pass exit. Because of a possible hydraulic jump at pass exit, accelerated wind speeds do not extend deeply into the Central Valley, especially during the night hours. It is also worth mentioning WRF's simulation of the lee side eddy at the northern end of the Altamont Pass exit near MTH. As WRF simulates the stable air intrusion over the low ridge and through the pass, mixing heights quickly rise at the pass exit causing horizontal and vertical eddies. The scattered nature of flow near MTH can be difficult to predict and could account for poor model performance at this location. These results match the findings of Gaberšek and Durran (2004) with regards to wind direction as well as the findings by Zangl (2003) and Gaberšek and Durran (2004) with regards to wind speed enhancement.

\section{d. Wind Power Modeling Performance}

Modeled hourly wind power was calculated from WRF-modeled winds and TKE using equations (1), (4), (5), (6), and (7) and summed for 24-hour periods to determine daily CF values for the six Altamont Pass Areas. Day One, Day Two, and Day Three performances of modeled daily $\mathrm{CF}$ were then compared to observed $\mathrm{CF}$ values for individual wind turbines within the same areas as well as daily averages for each area. Area 1 modeled daily CFs consistently under-predicted the observed area average (Figs. 18-22a). Area 3 modeled daily CFs consistently over-predicted the observed area average (Figs. 18-22c). Modeled daily CFs in Areas 2, 4, 5, and 6 were generally near or within one standard deviation of the observed area averages for all cases (Figs. 18-22 b, d, e, and f). 

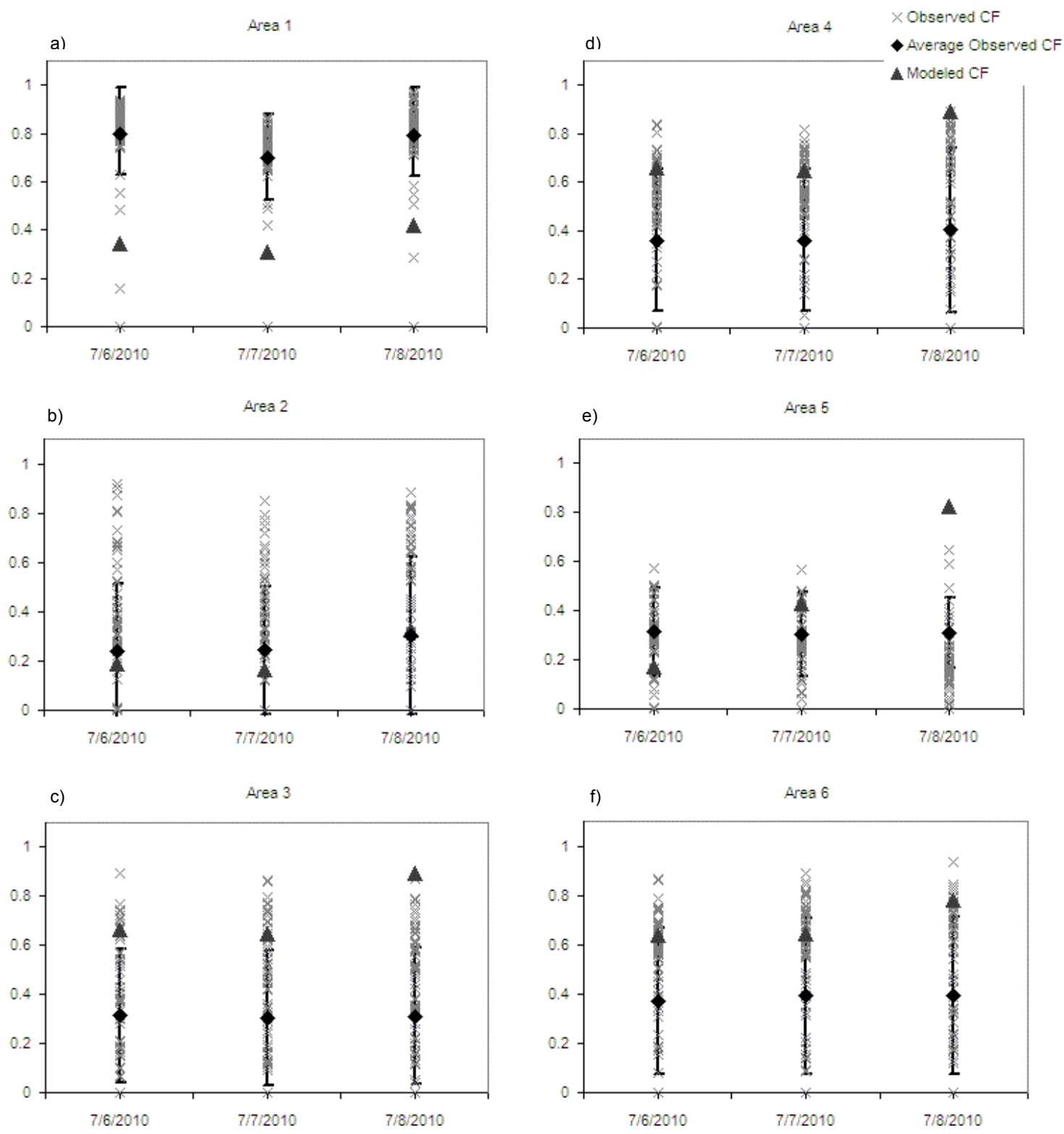

FIG. 18. Case 1 modeled daily CF (triangles), nearby turbine daily CF (Xs), area average observed daily CF (diamonds), and observed CF standard deviations for the six Altamont Pass observation Areas. For each panel, the first, second, and third vertical lines of data represent comparisons between observations and Day One, Day Two, and Day Three model output, respectively. 

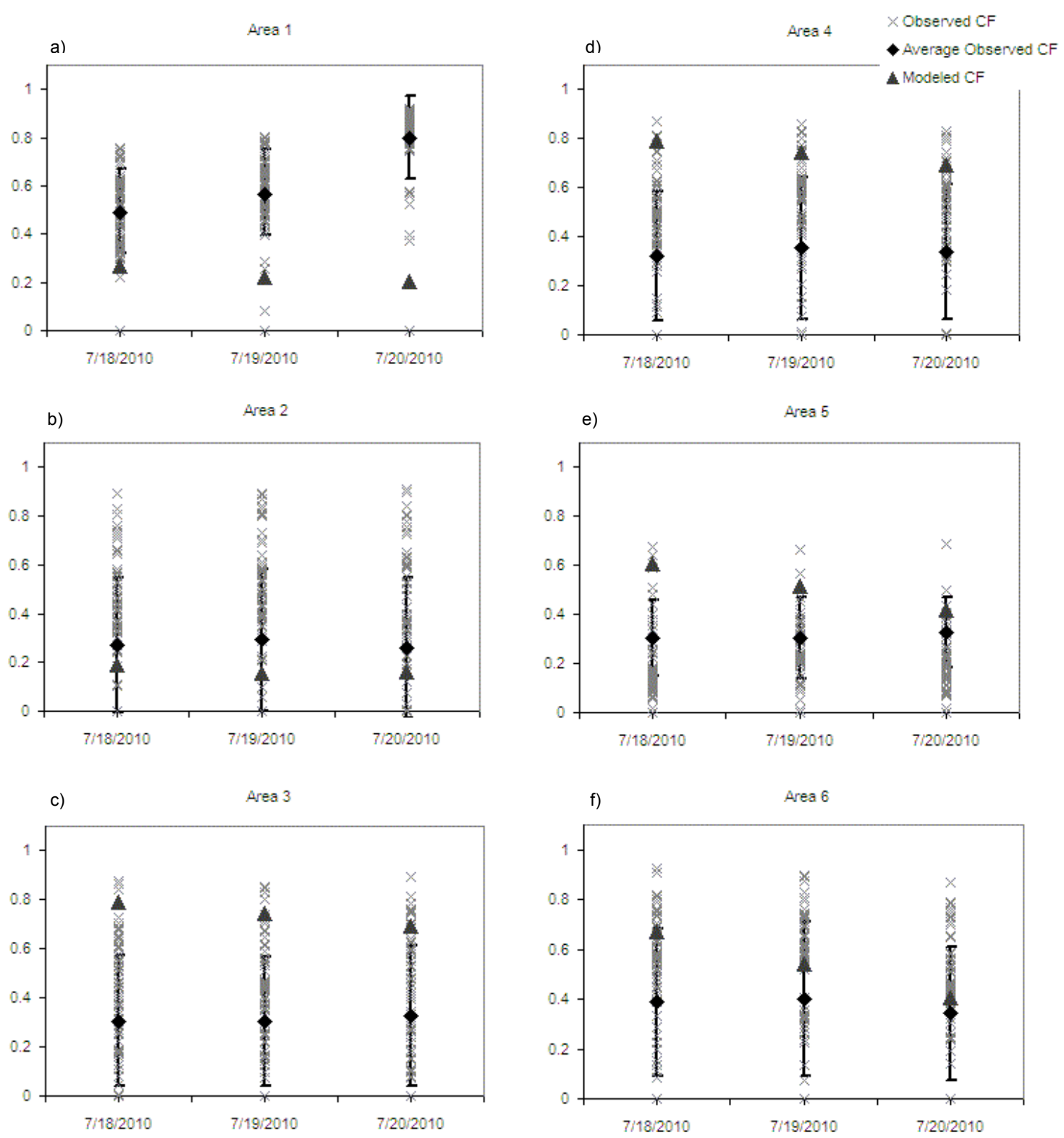

FIG. 19. Case 2 modeled daily CF (triangles), nearby turbine daily CF (Xs), area average observed daily CF (diamonds), and observed CF standard deviations for the six Altamont Pass observation Areas. For each panel, the first, second, and third vertical lines of data represent comparisons between observations and Day One, Day Two, and Day Three model output, respectively. 

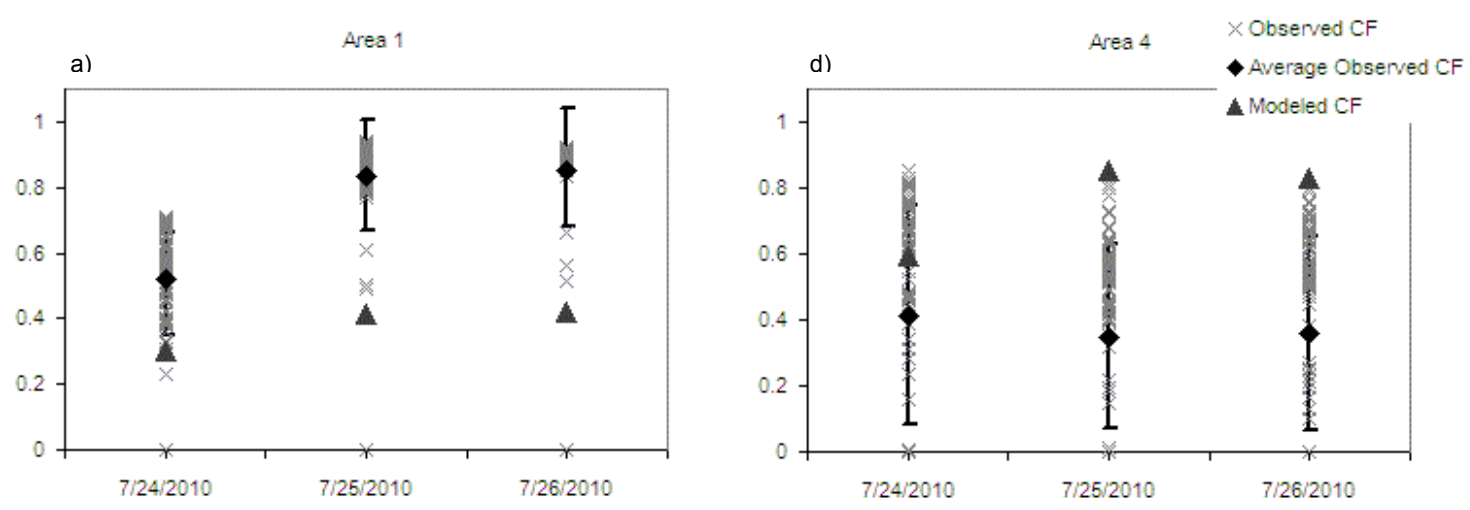

b)

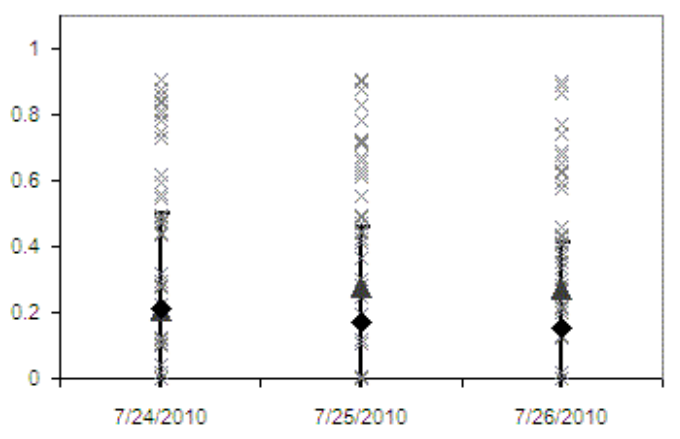

c)

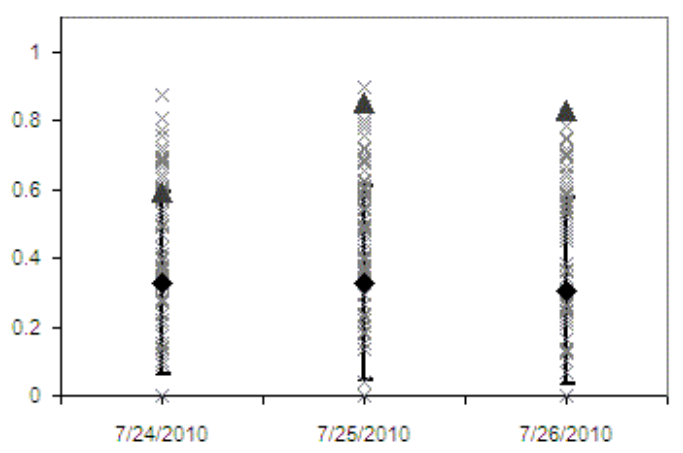

e)
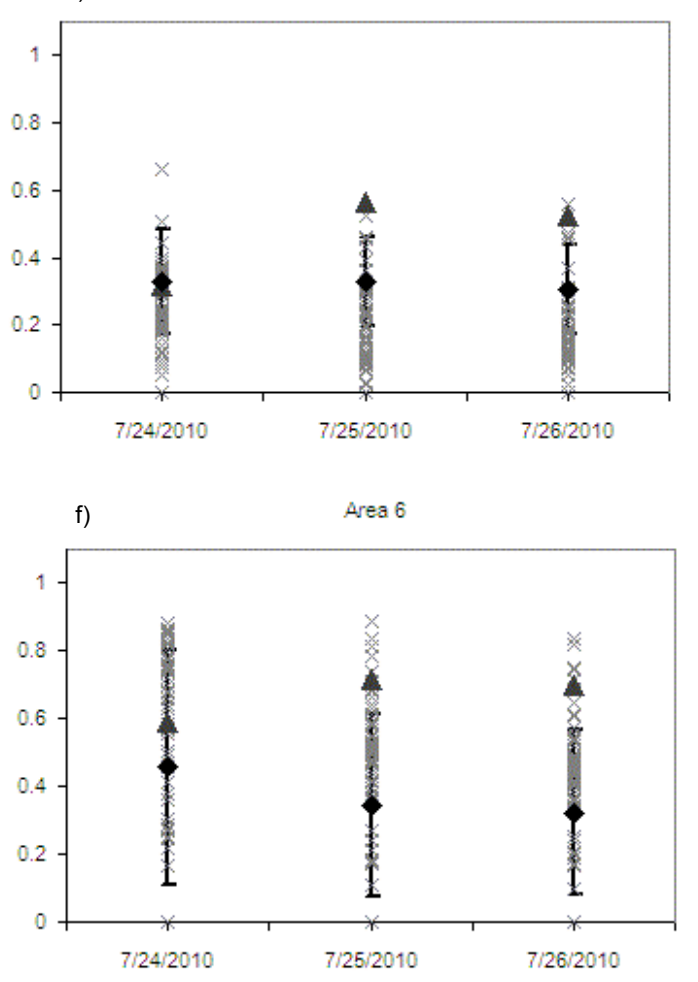

FIG. 20. Case 3 modeled daily CF (triangles), nearby turbine daily CF (Xs), area average observed daily CF (diamonds), and observed CF standard deviations for the six Altamont Pass observation Areas. For each panel, the first, second, and third vertical lines of data represent comparisons between observations and Day One, Day Two, and Day Three model output, respectively. 

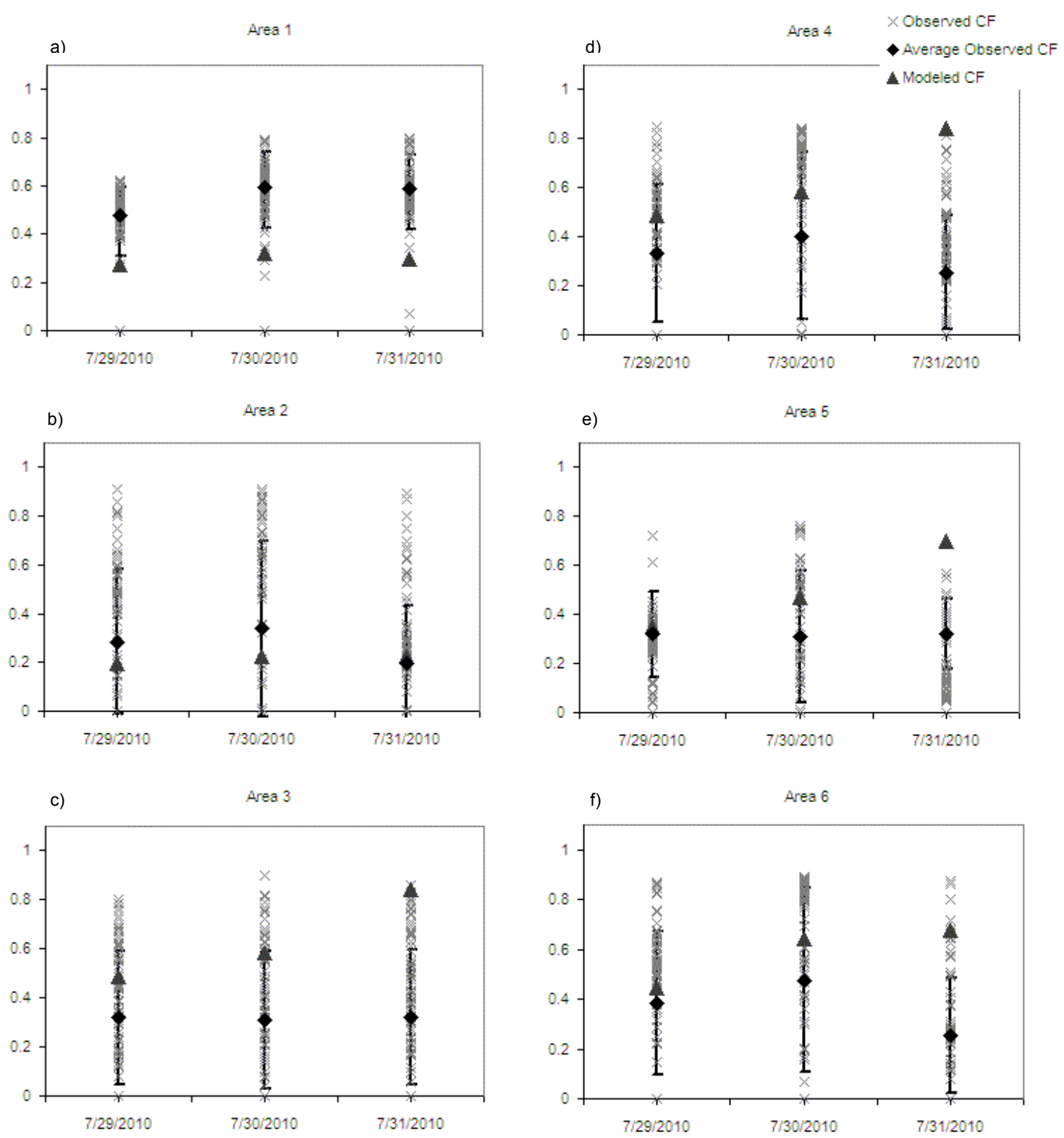

FIG. 21. Case 4 modeled daily CF (triangles), nearby turbine daily CF (Xs), area average observed daily CF (diamonds), and observed CF standard deviations for the six Altamont Pass observation Areas. For each panel, the first, second, and third vertical lines of data represent comparisons between observations and Day One, Day Two, and Day Three model output, respectively. 

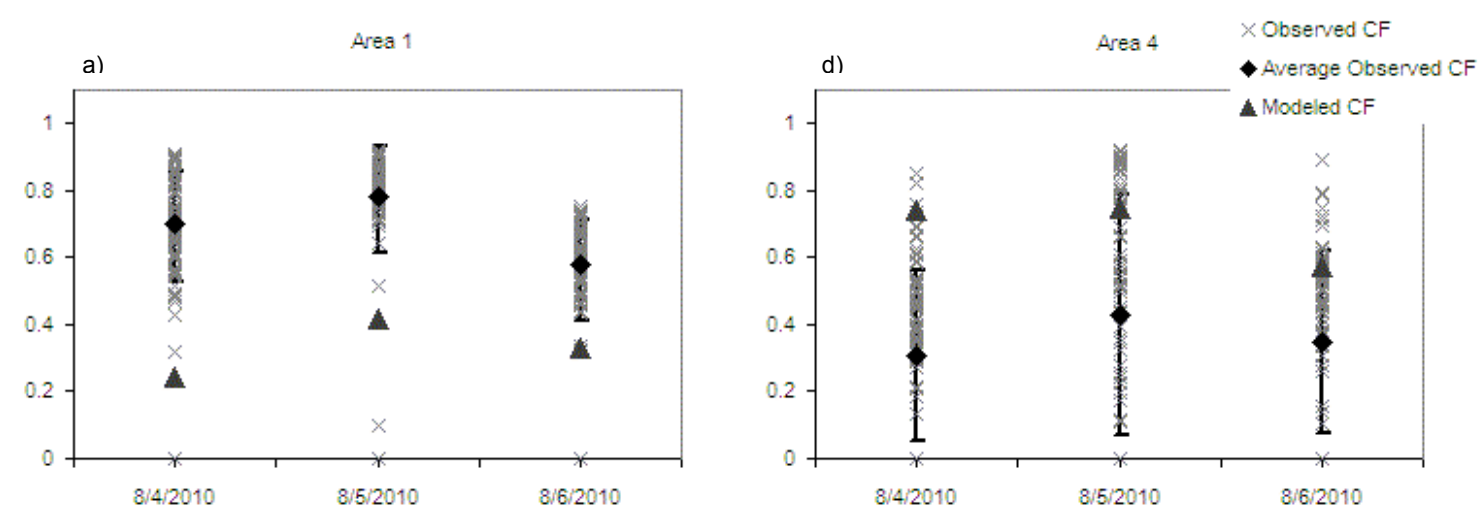

b)

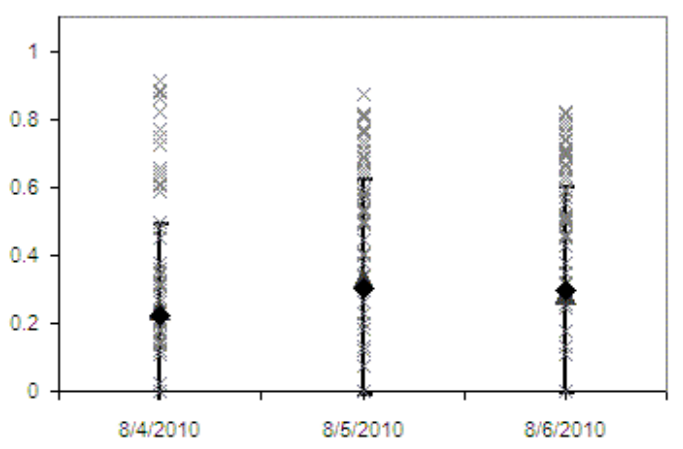

c)

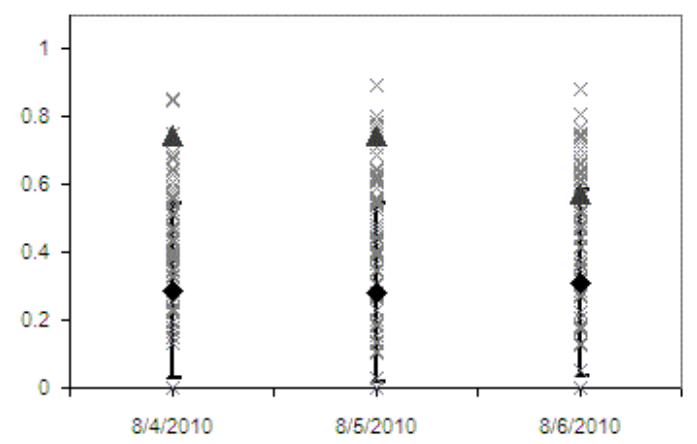

e)
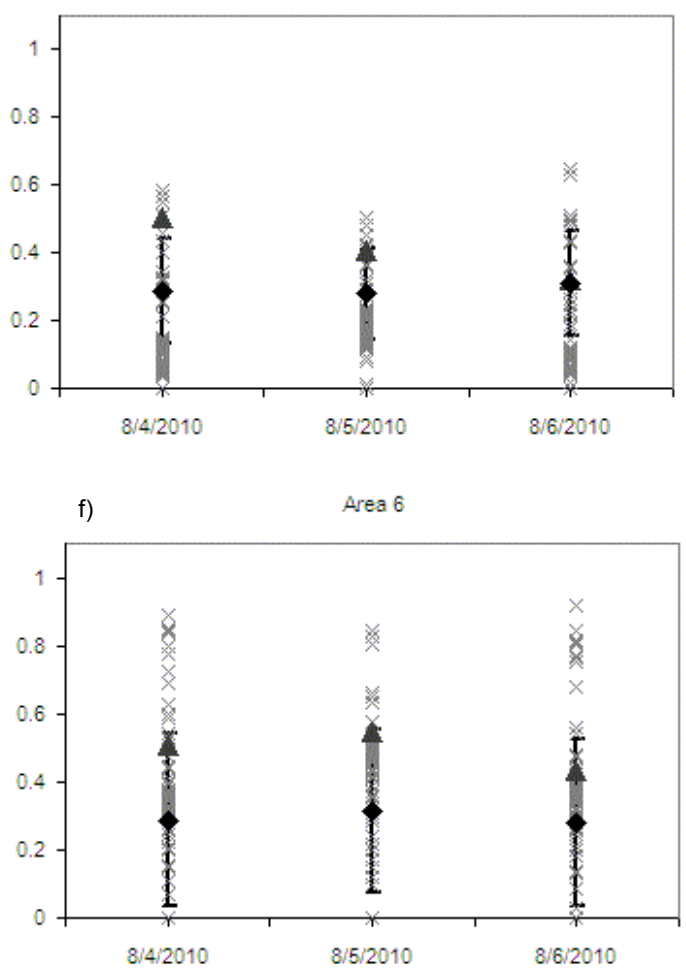

FIG. 22. Case 5 modeled daily CF (triangles), nearby turbine daily CF (Xs), area average observed daily CF (diamonds), and observed CF standard deviations for the six Altamont Pass observation Areas. For each panel, the first, second, and third vertical lines of data represent comparisons between observations and Day One, Day Two, and Day Three model output, respectively. 
TABLE 6. Modeled CF Performance.

\begin{tabular}{|c|c|c|c|c|}
\hline \multicolumn{5}{|c|}{ a. All Areas } \\
\hline $\begin{array}{l}\text { Time } \\
\text { Period }\end{array}$ & $\begin{array}{l}\text { Within Observed } \\
\text { Range }\end{array}$ & $\begin{array}{c}\text { Within } 1 \sigma \text { of } \\
\text { Observed Average }\end{array}$ & $\begin{array}{c}\text { Over- } \\
\text { Predicted }\end{array}$ & $\begin{array}{l}\text { Under- } \\
\text { Predicted }\end{array}$ \\
\hline Day 1 & $100 \%$ & $66 \%$ & $17 \%$ & $17 \%$ \\
\hline Day 2 & $90 \%$ & $53 \%$ & $30 \%$ & $17 \%$ \\
\hline Day 3 & $90 \%$ & $36 \%$ & $47 \%$ & $17 \%$ \\
\hline \multicolumn{5}{|c|}{ b. Excluding Areas 1 and 2} \\
\hline $\begin{array}{l}\text { Time } \\
\text { Period }\end{array}$ & $\begin{array}{c}\text { Within Observed } \\
\text { Range }\end{array}$ & $\begin{array}{c}\text { Within } 1 \sigma \text { of } \\
\text { Observed Average }\end{array}$ & $\begin{array}{c}\text { Over- } \\
\text { Predicted }\end{array}$ & $\begin{array}{l}\text { Under- } \\
\text { Predicted }\end{array}$ \\
\hline Day 1 & $100 \%$ & $75 \%$ & $25 \%$ & $0 \%$ \\
\hline Day 2 & $95 \%$ & $55 \%$ & $45 \%$ & $0 \%$ \\
\hline Day 3 & $90 \%$ & $25 \%$ & $75 \%$ & $0 \%$ \\
\hline \multicolumn{5}{|c|}{ c. Excluding Areas 1 and 3} \\
\hline $\begin{array}{l}\text { Time } \\
\text { Period }\end{array}$ & $\begin{array}{c}\text { Within Observed } \\
\text { Range }\end{array}$ & $\begin{array}{c}\text { Within } 1 \sigma \text { of } \\
\text { Observed Average }\end{array}$ & $\begin{array}{c}\text { Over- } \\
\text { Predicted }\end{array}$ & $\begin{array}{l}\text { Under- } \\
\text { Predicted }\end{array}$ \\
\hline Day 1 & $100 \%$ & $90 \%$ & $10 \%$ & $0 \%$ \\
\hline Day 2 & $95 \%$ & $75 \%$ & $25 \%$ & $0 \%$ \\
\hline Day 3 & $90 \%$ & $50 \%$ & $50 \%$ & $0 \%$ \\
\hline
\end{tabular}

Analyses of model performance for the individual day periods reveal more promising results; with Day One modeled CF results always within the observed CF range (Table 6a). Furthermore, Day One modeled CFs were within one standard deviation of the observed Area averages in 66 percent of the instances, and over (under) predicted daily CF in 17 (17) percent of the instances. Day Two modeled CFs were within the observed CF range in 90 percent of the instances. Furthermore, Day Two modeled CFs were within one standard deviation of the observed Area averages in 53 percent of the instances, and over (under) predicted daily CF in 30 (17) percent of the instances. Lastly, Day Three modeled CFs were also within the observed CF range in 90 percent of the instances. Furthermore, modeled CFs were within one standard deviation of the observed Area averages in 36 percent of the instances, and over (under) predicted wind power production in 47 (17) percent of instances. 
It was previously noted that Areas 1 and 2 exhibited lower accuracy wind speed performance when compared to the other four Altamont Pass Areas. When removing their results from the group statistics, daily CF performance improved (Table 6b). Overall, Day One, Day Two, and Day Three for Areas 3 through 6 showed modeled daily CFs within one standard deviation of the observed Area averages in 75, 55, and 25 percent of the instances, respectively. However, occurrences of daily CF over prediction increased, but occurrence of daily CF under prediction dropped to zero.

It was also previously noted that there was consistent under and over prediction of daily CF in Areas 1 and 3 (Figs. 18 - 22). Removing these results from the group statistics yields higher model performance improvements (Table 6c). Overall, Day One, Day Two, and Day Three for Ares 2, 4, 5, and 6 showed modeled daily CFs within one standard deviation of the observed Area averages in 90, 75, and 50 percent of the instances, respectively. Additionally, occurrences of daily CF over prediction were reduced in Day One and Day Two, while occurrences of daily CF under prediction in Day One, Day Two, and Day Three were reduced to zero.

Although modeled daily CFs were not exact, Day One and Day Two values were predominantly within one standard deviation of the observed Area average. Furthermore, when including Day Three values, there were only 6 out of 90 instances in which the modeled daily CF was outside the observed range. It is possible that the interpolation sites for each Altamont Pass Area may be better at representing the high or low end of the wind power production spectrum rather than the average. When ignoring the Areas whose model results exposed possible interpolation site deficiencies or consistent low 
model accuracy, WRF can model daily CFs in Altamont Pass at a high level of accuracy. It is also apparent that there was a tendency for increased modeled daily CF over prediction with longer lead time forecasts. In these cases, the level of over prediction was relatively consistent; and with consistencies model biases can be calculated and potentially used for adjusting the longer-range forecasts.

Additionally, wind power derived solely from WRF-modeled hub-height winds, i.e. no rotor area wind and stability shear corrections, was evaluated (not shown). It was found that using Wharton and Lundquist's (2010) $U_{\text {equiv }}$ for calculating wind power instead of only hub-height wind speeds resulted in 3 to 9 percent more accurate modeled daily CFs. While this is only a significant increase at a p-value of 0.3 , it could lead to substantial improvements in efficient energy planning. 


\section{Summary and Conclusions}

Efficient utilization of wind power at a given time requires accurate estimates of its potential contribution to the power network. Effective renewable energy planning requires a strong meteorological basis because accurate wind power forecasts heavily rely on accurate modeling of atmospheric dynamics, especially boundary layer winds and atmospheric stability. When considering that many wind farms are located within complex terrain, it can be a major challenge to accurately simulate the highly complex local atmospheric circulations. Given WRF's proven ability to more accurately model boundary layer dynamics in complex terrain, a series of five case study forecasts were conducted to test WRF model performance for the Altamont Pass wind farm near Livermore, California, USA. The WRF model was configured with three domains using two-way nesting to reach a horizontal resolution of $1 \mathrm{~km}$ over the region, with 52 vertical hydrostatic pressure levels, 18 of which were below 300 m AGL. Furthermore, using equivalent wind speed, wind power was calculated.

Modeled conditions were then compared to observations, and the overall results indicate good model performance for the regional near-surface winds, acceptable to good model performance for the Altamont Pass low-level winds, and good model performance for Altamont Pass capacity factor simulations. Moreover, while modeled hour-to-hour variance was not exact, WRF-modeled wind speeds were close to those observed. More importantly the magnitude of model error is relatively small compared to the average local wind speeds. Combined with good agreement between both modeled and observed wind direction and atmospheric stability, modeled capacity factors were within the 
observed range in 93 percent of the instances. Furthermore, Day One and Day Two daily CF forecasts were predominantly within one standard deviation of each Area's observed average. Therefore, WRF modeled winds and derived wind power can be used as a wind power forecasting tool for Altamont Pass and potentially other coastal complex terrain regions.

Sources of error in the WRF model forecasts can generally be linked to errors fed into the WRF model boundaries by NAM. However, internal model errors do arise for a host of different reasons, and some model runs were much more accurate than others. However, as confirmed by this analysis, the first 48 hours of each model run generally exhibit good performance. While five case studies were evaluated, in order to establish a more robust conclusion more model runs and evaluations should be performed. Furthermore, with more studies conducted, model biases can be determined and adjusted for, as in any forecasting tool. Given the preliminary results that WRF can aptly simulate regional atmospheric conditions, $\mathrm{WRF}$ is now used as a real-time forecasting system at San José State University. 


\section{References}

Anderson, J. R., E. E. Hardy, J. T. Roach, and R. E. Witmer, 1976: A land use and land cover classification system for use with remote sensor data. U.S. Geological Survey Professional Paper 964, 41 pp.

Archer, C. L., M. Z. Jacobson, 2005: The Santa Cruz Eddy. Part II: Mechanisms of Formation. Mon. Wea. Rev., 133, 2387-2405. DOI: 10.1175/MWR2979.1

Barry, R. G. 1992: Mountain Weather and Climate. $2^{\text {nd }}$ ed. Routledge, 402 pp.

Bathurst, G. N., J. Weatherill, and G. Strbac, 2002: Trading Wind Generation in Short Term Energy Markets. Power Systems, IEEE Transactions on, 17, 782-789.

Brown, B. G., R. W. Katz, and A. H. Murphy, 1984: Time Series Models to Simulate and Forecast Wind Speed and Wind Power. Jour. of App. Met., 23, 1184-1195.

Burk, S. D., W. T. Thompson, 1996: The Summertime Low-Level Jet and Marine Boundary Layer Structure along the California Coast. Mon. Wea. Rev., 124, 668686.

Doran, J. C. and S. Zhong, 2000: Thermally Driven Gap Winds into the Mexico City Basin. Jour. of App. Met., 39, 1330-1340.

Doyle, J. D. and R. B. Smith, 2003: Mountain waves over the Hohe Tauern: Influence of Upstream Diabatic Effects. Q. J. R. Meteorol. Soc., 129, 799-823, DOI:10.1256

Dudhia, J., 1989: Numerical Study of Convection Observed During the Winter Monsoon Experiment using a Mesoscale Two-Dimensional Model. Jour. of Atmos. Sci., 46, 3077-3107. 
Fosberg, M. A. and M. J. Schroeder, 1966: Marine Air Penetration in Central California. Jour. of App. Met., 5, 573-589.

Gaberšek, Saša, Dale R. Durran, 2004: Gap Flows through Idealized Topography. Part I: Forcing by Large-Scale Winds in the Non-Rotating Limit. Jour. of Atmos. Sci., 61, 2846-2862.

Gaberšek, Saša, Dale R. Durran, 2006: Gap Flows through Idealized Topography. Part II: Effects of Rotation and Surface Friction. Jour. of Atmos. Sci., 63, 2720-2739.

Gazzilli, G., S. Palmieri, A. M. Siani, and G. R. Casale, 2001: In search of Mountain Sites Suitable for Wind Farms in the Mediterranean Area using a Diagnostic Wind Model. Meteorol. Appl., 8, 205-208.

Hanna, S. R., R. Yang, 2001: Evaluations of Mesoscale Models' Simulations of NearSurface Winds, Temperature Gradients, and Mixing Depths. Jour. of App. Met., 40, 1095-1104.

Janjic, Z. I., 1996: The Surface Layer in the NCEP Eta Model. 11th Conf. on NWP, Norfolk, VA, Amer. Met. Soc., 354-355

Janjic, Z. I., 2003: The NCEP WRF Core and Further Development of Its Physical Package. 5th International SRNWP Workshop on Non-Hydrostatic Modeling, Bad Orb, Germany, 27-29 October.

Jaramillo, O. A., and M. A. Borja, 2004: Wind Speed Analysis in La Ventosa, Mexico: a Bimodal Probability Distribution Case. Renewable Energy, 29, 1613-1630.

Jiménez, P. A., E. García-Bustamante, J. F. González-Rouco, J. Navarro, J. P. Montávez, J. V. G. de Arellano, J. Dudhia, and A. Muñoz-Roldan, 2010: Surface Wind 
Regionalization over Complex Terrain: Evaluation and Analysis of a HighResolution WRF Simulation. Jour. of App. Met. and Clim., 49, 268-287.

Kain, J. S., and J. M. Fritsch, 1990: A One-Dimensional Entraining/Detraining Plume Model and Its Application in Convective Parameterization. Jour. of Atmos. Sci., 47, 2784-2802.

Kain, J. S., and J. M. Fritsch, 1993: Convective Parameterization for Mesoscale Models: The Kain-Fritsch Scheme. The Representation of Cumulus Convection in Numerical Models, Meteor. Monogr., No 46, Amer. Met. Soc. 165-170.

Kariniotakis, G., P. Pinson, N. Siebert, G. Giebel, and R. Barthelmie, 2004: The State of the Art in Short-Term Prediction of Wind Power-from an Offshore Perspective. IEEE, 20-21.

Mlawer, E. J., S. J. Taubman, P. D. Brown, M. J. Iacono, and S. A. Clough, 1997: Radiative Transfer for Inhomogeneous Atmospheres: RRTM, a Validated Correlated-k Model for the Longwave. J. Geophys. Res., 102, 16 663-16 682.

Reid, S. J., R. Turner, 2001: Correlation of Real and Model Wind Speeds in Different Terrains. Weather and Forecasting, 16, 620-627.

Rife, D. L., C. A. Davis, Y. Liu, and T. T. Warner, 2004: Predictability of Low-Level Winds by Mesoscale Meteorological Models. Mon. Weather Rev., 132, 2553-569.

Rogers, E., T. Black, B. Ferrier, Y. Lin, D. Parrish, and G. DiMego, 2001: Changes to the NCEP Meso Eta Analysis and Forecast System: Increase in Resolution, New Cloud Microphysics, Modified Precipitation Assimilation, Modified 3DVAR Analysis. NWS Technical Procedures Bulletin, 488, 15. 
Sezgen, O., C. Marnay, and S. Bretz, 1998: Wind Generation in the Future Competitive California Power Market. Ernest Orlando Lawrence Berkeley National Laboratory LBNL-41134, 64 pp.

Sharp, J., and C. F. Mass, 2004: Columbia Gorge Gap Winds: Their Climatological Influence and Synoptic Evolution. Thesis, Dept. of Atmospheric Sciences, University of Washington, $56 \mathrm{pp}$.

Skamarock, W. C., J. B. Klemp, J. Dudhia, D. O. Gill, D.M. Barker, W. Wang, and J. G. Powers, 2008: A Description of the Advanced Research WRF Version 3. NCAR Tech. Note TN-475+STR. 125 pp.

Wagner, R., I. Antoniou, S. M. Pedersen, M. S. Courtney, and H. E. Jørgensen, 2009: The Influence of the Wind Speed Profile on Wind Turbine Performance Measurements. Wind Energy, 12, 348-362.

Wharton, S., and J. Lundquist, 2010: Atmospheric Stability Impacts on Power Curves of Tall Wind Turbines-An Analysis of a West Coast North American Wind Farm. Technical report, Lawrence Livermore National Laboratory (LLNL), LLNL-TR424425, $73 \mathrm{pp}$.

Whiteman, C. D., 2000: Mountain Meteorology: Fundamentals and Applications. Oxford University Press, 376 pp.

Wiser, R., and M. Bolinger, 2008: Annual Report on U.S. Wind Power Installation, Cost and Performance Trends: 2007. U.S. DOE Publication DOE/GO-102008-2590. 
Žagar, N., M. Žagar, J. Cedilnik, G. Gregorič, and J. Rakovec, 2006: Validation of Mesoscale Low-Level Winds Obtained by Dynamical Downscaling of ERA40 over Complex Terrain. Tellus A, 58, 445-455.

Zangl, G., 2003: Orographic Gravity Waves Close to the Nonhydrostratic Limit of Vertical Propagation. Jour. of Atmos. Sci., 60, 2045-2063.

Zaremba, L. L., and J. J. Carroll, 1999: Summer Wind Flow Regimes over the Sacramento Valley. Jour. of App. Met., 38, 1463-1473. 


\section{APPENDIX A}

\section{Acronyms}

\begin{tabular}{|c|c|}
\hline $\mathrm{ACC}$ & Anomaly Correlation \\
\hline AGL & Above Ground Level \\
\hline CARB & California Air Resource Board \\
\hline $\mathrm{CF}$ & Capacity Factor \\
\hline CWOP & Citizen Weather Observer Program \\
\hline LLNL & Lawrence Livermore National Laboratories \\
\hline LSMF & Late Spring through Mid Fall season \\
\hline LT & Local Time \\
\hline MAE & Mean Absolute Error \\
\hline METAR & METeorological Terminal Air Report \\
\hline MSL & above Mean Sea Level \\
\hline NAM & North American Mesoscale Model \\
\hline RAWS & Remote Automated Weather System \\
\hline RMSE & Root Mean Square Error \\
\hline USGS & U.S. Geologic Survey \\
\hline UTC & Universal Time Coordinated \\
\hline WRF & Weather Research and Forecasting Model \\
\hline
\end{tabular}

